\title{
Exposure to Classroom Poverty and Test Score Achievement: Contextual Effects or Selection? ${ }^{1}$
}

\author{
Douglas Lee Lauen and S. Michael Gaddis \\ University of North Carolina at Chapel Hill
}

It is widely believed that impoverished contexts harm children. Disentangling the effects of family background from the effects of other social contexts, however, is complex, making causal claims difficult to verify. This study examines the effect of exposure to classroom poverty on student test achievement using data on a cohort of children followed from third through eighth grade. Cross-sectional methods reveal a substantial negative association between exposure to high-poverty classrooms and test scores; this association grows with grade level, becoming especially large for middle school students. Growth models, however, produce much smaller effects of classroom poverty exposure on academic achievement. Even smaller effects emerge from student fixedeffects models that control for time-invariant unobservables and from marginal structural models that adjust for observable time-dependent confounding. These findings suggest that causal claims about the effects of classroom poverty exposure on achievement may be unwarranted.

Scholars have spent decades researching and debating the influence of school and neighborhood context on academic achievement, aspirations, and attitudes (Wilson 1959; Alexander and Eckland 1975; Felmlee and Eder 1983; Rumberger and Willms 1992; Crosnoe 2009). The scholarly consensus is that high-socioeconomic status schools and neighborhoods posi-

\footnotetext{
${ }^{1}$ We gratefully acknowledge the support of the Spencer Foundation and the North Carolina Education Research Data Center for providing the data. We thank Kyle Crowder, Patrick Curran, Mike Foster, Eric Grodsky, Ashu Handa, Christopher Jencks, Roz Mickelson, Mike Shanahan, Chris Wiesen, and especially Stephen R. Cole for their assistance and many use- 
tively affect individual academic outcomes (Willms 1986; Brooks-Gunn et al. 1993; Entwisle, Alexander, and Olson 1994), whereas high-poverty schools and neighborhoods negatively affect academic outcomes (Crane 1991; Harding 2003; South, Baumer, and Lutz 2003). For example, Coleman and colleagues, in their seminal Equality of Educational Opportunity report, argued that peer effects were strong predictors of academic achievement: "the social composition of the student body is more highly related to achievement, independent of the student's own social background, than is any other school factor" (Coleman et al. 1966, p. 325). Social science evidence on contextual effects has informed social science theory and educational policy in the United States, which for the past four decades has sought to mix students by racial background and, more recently, by poverty status (Kahlenberg 2001; Bazelon 2008; Grant 2009). The relevance of contextual effects research is demonstrated by the prominent role such research played in the recent social science statement submitted as an amicus curiae brief in a 2007 school assignment Supreme Court case (Orfield, Frankenberg, and Garces 2008).

The scholarly consensus on contextual effects, however, rests largely on cross-sectional studies, which do not provide a strong basis for causal inference. Selection bias, perhaps the most important threat to the validity of point-in-time studies, can give rise to what Hauser (1970) termed the "contextual fallacy": "The contextual method rests on the arbitrary identification of residual group differences in the dependent variable with correlated aspects of group composition on an independent variable. . . The only way to eliminate such correlations is to assign individuals randomly to groups, and this is impossible with observational data" (p. 660). Recent work in sociology (Harding 2003; Crosnoe 2009) and in economics (Solon, Page, and Duncan 2000; Hoxby and Weingarth 2005; Hanushek, Kain, and Rivkin 2009) attempts to reduce bias in contextual effects through propensity score matching and weighting, comparison of sibling and neighbor correlations, fixed effects, instrumental variables, and natural experiments. Experimental evidence on the effect of changes in school and neighborhood context and academic achievement has emerged from the Moving to Opportunity program (Orr et al. 2003; Sanbonmatsu et al. 2006; Kling, Liebman, and Katz 2007). Some of this recent work raises important questions about whether causal inferences about contextual effects are warranted (Mouw 2006). Finally, very few longitudinal contextual effects studies account for time-dependent confounding. Time-dependent confounders, which predict both future treatment and future outcome conditional on past treatment,

ful comments. Direct correspondence to Douglas Lee Lauen, Department of Public Policy, University of North Carolina at Chapel Hill, Abernethy Hall, CB \#3435, Chapel Hill, North Carolina 27599-3435. E-mail: dlauen@unc.edu 
present a challenge to estimating unbiased treatment effects. For example, in estimating the effect of poverty context on child outcomes, one may wish to control for intermediate outcomes such as educational experiences while in school (such as assignment to gifted or remedial programs or being retained in a grade). If these intermediate outcomes then predict both future treatment and future outcome, standard methods - controlling for these factors, omitting them, or controlling for baseline values - can produce biased estimates (Robins, Hernán, and Brumback 2000; Hong and Raudenbush 2008). Methods for addressing treatment effect bias from time-dependent confounding have been developed in epidemiology by Robins and colleagues (Robins 1999; Hernán, Brumback, and Robins 2000; Robins et al. 2000; Cole and Hernán 2008). Recent work using these methods has demonstrated negative effects of exposure to neighborhood concentrated disadvantage on verbal ability (Sampson, Sharkey, and Raudenbush 2008).

This study uses longitudinal data to estimate the effect of exposure to a high-poverty classroom on elementary and middle school students' test scores. These data include interval metric and vertically equated mathematics and reading test scores and variation across time in classroom-level poverty from a complete cohort of public school children in grades 3-8 in the state of North Carolina from 2001 to 2006 (more than 500,000 studentyear observations). The study contributes to contextual effects research by carefully specifying and accounting for bias from omitted and mismeasured time-invariant student and family background characteristics. We report effects of classroom poverty based on three measures: attendance in a high-poverty classroom (i.e., one in the top quartile of the classroom poverty distribution), cumulative exposure to a high-poverty classroom, and continuous classroom poverty. We first present cross-sectional multilevel estimates of the association between classroom poverty and math test score. These estimates reproduce the negative effects reported in previous research with cross-sectional designs. The strength of the cross-sectional association increases with grade level. By eighth grade, these estimates are particularly large, which suggests that the cognitive disadvantage of classroom poverty exposure appears to accumulate over time. Growth models produce very small negative effects on two of the three measures (high-poverty classroom and continuous classroom poverty) and larger negative effects on the other (cumulative exposure to a high-poverty classroom). To address endogenous self-selection based on fixed unobservables, we present student fixed-effects estimates, which remove between-student confounding (Allison 2009). This approach controls for time-invariant unmeasured and mismeasured aspects of student and family background that may predict both family choice of neighborhood and school and test score achievement. These models produce estimates distinguishable from zero but of negligible size. We also estimate marginal structural models with inverse probability of treatment weighting 
American Journal of Sociology

to address time-dependent confounding (Robins et al. 2000; Hong and Raudenbush 2008). These models produce nonsignificant effects on math and very small effects of classroom poverty on reading, which suggests that our estimates are robust to two different threats to validity.

The effects reported do not suggest that all children's life course outcomes are insensitive to classroom poverty, but they raise important doubts about the causal status of the effect of classroom poverty on student test scores among children and young adolescents, an implication that we discuss in our conclusion.

\section{THEORY AND EVIDENCE ABOUT CONTEXTUAL EFFECTS}

Drawing on the theory and evidence from the contextual effects literature on school and neighborhood effects, we suggest four explanations specific to the effect of classroom poverty on student achievement growth for children and young adolescents (Jencks and Mayer 1990; Harris 2010; Willms 2010). First, classroom poverty may have a negative effect on student achievement growth due to institutional mechanisms: low parental involvement in schooling, lower-quality teachers, lower expectations, slower pacing, and less rigorous curriculum (Barr and Dreeben 1983; Sedlak et al. 1986; Lee, Bryk, and Smith 1993). Second, classroom poverty may have a negative effect due to contagion mechanisms: the downward leveling norms of predominantly low-achieving peers (Crane 1991; Harding 2003; South et al. 2003). Third, classroom poverty may have a positive effect due to relative deprivation mechanisms: the lack of competitive pressure and a lower average comparison group (Davis 1966; Attewell 2001; Crosnoe 2009). Fourth, classroom poverty may have no effect on student achievement growth once student background is properly controlled, which could point to a selection mechanism, that is, that the apparent effect of context is due to the selection of families into schools and classrooms based on factors that are also correlated with test score growth and classroom poverty level (Hauser 1970; Mouw 2006).

In the next section, we summarize the cross-sectional contextual effects literature, organizing studies by the type of effects reported (i.e., positive effect of affluent context, negative effect of affluent context, no significant effect). We then discuss findings from alternative designs (longitudinal and experimental). To conclude our review, we critique the existing literature and outline the contributions of our study.

\section{Cross-Sectional Evidence}

Cross-sectional contextual effects research generally finds a positive association between socially desirable youth outcomes and average school 
and neighborhood socioeconomic status (SES). For example, studies find positive effects of school mean parental education on standardized test scores (Entwisle et al. 1994) and four-year college enrollment (Choi et al. 2008), positive effects of school mean SES on grades and attainment (Willms 1986), and negative effects of the school mean poverty rate on academic self-esteem, educational aspirations and expectations, and standardized test scores (Battistich et al. 1995). Neighborhood effects research finds positive effects of high-poverty neighborhoods on teenage pregnancy and high school dropout rates (Crane 1991; Harding 2003), negative effects of early childhood neighborhood poverty on educational attainment measured in adulthood (Entwisle, Alexander, and Olson 2005), and negative effects of neighborhood deprivation on educational attainment in Scotland (Garner and Raudenbush 1991). Similarly, low levels of neighborhood poverty have been associated with positive effects on educational attainment (Duncan 1994), positive effects on standardized test scores (Entwisle et al. 1994), positive effects on IQ, and negative effects on high school dropout rates (BrooksGunn et al. 1993). Finally, there is some evidence of positive additive effects of both high-SES neighborhoods and high-SES schools on earning a bachelor's degree (Owens 2010).

There is also evidence to support the hypothesis that affluent peers and neighbors can have negative effects on youth outcomes. Scholars posit that relative deprivation, sometimes referred to as the "frog pond effect," discourages and depresses the aspirations, achievement, and attainment of students in more affluent schools (Davis 1966; Marsh and Parker 1984; Bachman and O'Malley 1986; Marsh 1987; Jencks and Mayer 1990; Attewell 2001; Crosnoe 2009). Though it may be advantageous to associate with affluent neighbors and peers, high-achieving peers may harm aspirations, grades, curricular placement, and other academic outcomes, especially when students must compete for scarce resources. For example, Davis (1966) investigated whether the theory of relative deprivation explained college student career and graduate school application decisions. His results indicate that school mean achievement may have a negative effect on career aspirations, suggesting that students in more competitive environments may remove themselves from contention for high-status careers and graduate schools. Another study finds that students in elite public high schools suffer a competitive disadvantage in entering elite colleges due to the importance of class rank in the college admissions process (Attewell 2001). This disadvantage may produce an organizational adaptation to triage resources in favor of the top students. Therefore, students in high but not the highest quantiles of class rank may receive worse grades and take less advanced courses than they would if they had attended a less elite public high school.

On the other hand, peers may have little or no influence on individual outcomes. Contextual effects of classroom poverty and affluence may simply 
American Journal of Sociology

reflect self-selection (Hauser 1970; Evans, Oates, and Schwab 1992; Leventhal and Brooks-Gunn 2000; Quigley and Raphael 2008). Important omitted and mismeasured family and student background characteristics may be causal determinants of both test score achievement and how individuals sort into neighborhoods and schools. Controlling for these factors might greatly reduce the unadjusted difference in outcomes between students from high- and low-poverty contexts. For instance, Alexander et al. investigate the nature of school effects and find that controlling for individual SES reduces the effect of school mean SES on college plans to near zero. Their conclusion is that "the school SES influences are shown to result to a considerable degree simply from SES differences in the kinds of students attending various schools" (1979, p. 235). Cross-sectional research that controls for prior test scores or grades has reported relatively small and statistically insignificant contextual effects. In a study of high school students, Gamoran (1987) finds very minimal and mostly nonsignificant effects of school mean SES on test score outcomes in six subjects while controlling for prior achievement. The author incorporates mediators of the contextual effect, such as types of coursework and tracking variables, and concludes that within-school differences in opportunity to learn are more important than, and perhaps provide explanations for, contextual effects.

\section{Alternative Designs of Contextual Effects}

Much of the research discussed thus far employs cross-sectional designs, which ignore the cumulative nature of students' educational development and do not adequately control for self-selection bias. This section summarizes research from two strands of literature: studies with longitudinal designs and neighborhood relocation experiments.

A point-in-time study captures the effect of schooling in a focal year as well as the effects of prior educational experiences and student and family background. Reviews of the literature note the importance of controlling for exogenous factors (i.e., those that do not depend on type of neighborhood or school) and call for more longitudinal designs (Jencks and Mayer 1990; Duncan and Raudenbush 1999; Galster et al. 2007; Saporito and Sohoni 2007; Harris 2010). Rumberger and Palardy (2005) examine the effect of school SES composition on test score growth in high school with data from the National Education Longitudinal Study, a nationally representative database. They use a three-level growth model (time within student within school), finding that the predictive power of school SES on composite test score growth is as strong as family SES (a .12 $\sigma$ effect size for individual SES and a .11 $\sigma$ effect size for school SES). As the authors note, these effects on a standardized composite test score mask important differences across different subjects. Effects of school SES on test score growth in math 
and reading are relatively small (.05 $\sigma$ and $.06 \sigma$, respectively), while effects in science and history, perhaps because of differential opportunity to learn these subjects in low-SES high schools, are larger $(.21 \sigma$ and $.14 \sigma$, respectively). Another contribution of this study is showing that the effect of school SES is explained by teacher expectations, the amount of homework students do, course taking, and student perceptions of school safety. Although this study uses an impressive array of control variables to adjust for observable differences in student populations that could confound the school SES effect, its design does not permit ruling out bias from the sorting of students into schools based on unobservables. It also does not account for the problem of time-dependent confounding, which could arise if a student's school SES is a function of lagged values of school SES and lagged values of the outcome.

The gold standard for addressing unobservables in contextual effects research is experimental design (Kling et al. 2007; Sampson 2008). Although no experiment conducted to date allows for direct examination of school contextual effects, evaluations of a housing relocation program, Moving to Opportunity (MTO), provide suggestive evidence about the impact of changes in both neighborhood and school context (see DeLuca and Dayton [2009] for a review of this research). The MTO experiment randomly assigned participants to three groups: a treatment group that was provided a Section 8 voucher and allowed to move without restrictions, another treatment group provided a rental assistance voucher but allowed to move only to a census tract with less than $10 \%$ poverty, and a control group offered no voucher to move. While early results indicated a number of positive academic outcomes for the treatment groups, later follow-up studies found that these positive results dissipated. Children in the treatment group showed no academic improvement, except for black children's reading test scores, and were in only marginally better schools than before the switch (Orr et al. 2003; Sanbonmatsu et al. 2006; Kling et al. 2007).

To our knowledge only two studies of poverty context account for timedependent confounding in modeling effects on children's cognitive outcomes. In the first, Sampson et al. (2008) examine the effect of changes in neighborhood concentrated disadvantage on children's verbal ability across three waves of African-American families in the Project on Human Development in Chicago Neighborhoods study. To address the problem of time-varying confounding, the authors estimate a marginal structural model (MSM) with inverse probability of treatment weighting (IPTW) and report that the effect of neighborhood concentrated disadvantage on children's verbal ability is large and negative, equivalent to missing a year of school. In the second, Sharkey and Elwert (2011) also estimate an MSM with IPTW and find that multigenerational neighborhood poverty has a negative effect on children's cognitive ability. 
In summary, existing research on school contextual effects rests primarily on a base of cross-sectional designs of correlational evidence. One study of school contextual effects employs a longitudinal design but ignores the problem of unobserved heterogeneity and time-dependent confounding. Housing relocation studies provide evidence about changes in neighborhood, which also involve changes in school context, but suffer from limitations of generalizability to nonpoor and nonminority populations and leave unexamined the effects of increases in classroom poverty. Two studies from the neighborhood effects literature use appropriate techniques to address timedependent confounding and report negative effects of neighborhood poverty on children's cognitive ability.

The present study makes a contribution to existing research on school contextual effects by employing a rigorous longitudinal research design. First, we estimate a quadratic growth curve model over six years (grades 3-8) that relates the effect of changes in classroom poverty to changes in students' test score achievement. Second, we address selection bias by including student fixed effects in our growth model. A large literature in economics and a growing literature in sociology (e.g., Jacobs and Carmichael 2001; Mouw 2003; England, Allison, and Wu 2007; Jacobs and Tope 2007; Kocak and Carroll 2008; Schneiberg, King, and Smith 2008) use fixed-effects methods to control for time-invariant unobserved heterogeneity. ${ }^{2}$ These models, which require treatment variation within units over time, remove confounding bias that can emerge from omitted observable, mismeasured, or unobservable time-invariant student or group characteristics (Wooldridge 2003; Halaby 2004; Mouw 2006; Allison 2009). In the present context, this technique accounts for important student-level confounders such as low birth weight, early childhood education, and genetic factors, as well as family-level confounders such as parental IQ and class background. Third, following Sampson et al. (2008) and Sharkey and Elwert (2011), we account for time-dependent confounding by producing growth model estimates with IPTW.

Unlike most prior school contextual research, we measure classroom poverty at the classroom level rather than at the school level, which, because of the nonrandom sorting of students to classrooms and middle school tracking based on achievement level, may produce less valid estimates of classroom poverty effects. We measure classroom poverty in three ways: attendance in a high-poverty classroom (i.e., in the top quartile of the classroom poverty distribution); cumulative exposure to a high-poverty classroom, which more accurately reflects the time-varying exposure to context over

\footnotetext{
${ }^{2}$ Here fixed effects refers to the panel data technique of using differencing or including indicator variables to control for unit-specific effects, not fixing random effects to zero or fixed (vs. random) coefficients in a random-effects model.
} 
a youth's life course; and continuous classroom poverty (defined as the percentage receiving a free or reduced-price lunch). We examine the effects of both increases and decreases in classroom poverty among a diverse population of students enrolled in the North Carolina public school system (a population that includes in large numbers whites, blacks, Hispanics, nonpoor, and poor students in urban, suburban, and rural locales). ${ }^{3}$ Finally, we focus on elementary and middle school student test score growth for two reasons: (1) the effects of classroom poverty on younger students are relatively understudied, and (2) classroom poverty has been shown to be more strongly related to cognitive and achievement outcomes than to behavioral and health outcomes (Duncan and Brooks-Gunn 1997).

\section{DATA}

This project uses test score and related data for one cohort of public school students in North Carolina beginning in grade 3 in 2001 through grade 8 in 2006. North Carolina is a particularly appropriate setting for this analysis because it is one of the few states to consistently administer comparable tests over this time period, with scores produced from a three-parameter logistic item response theory (IRT) model and scored on a developmental scale to allow computation of growth across grade levels. ${ }^{4}$ The sample includes more than 500,000 student-year observations, beginning with about 100,000 third graders in 2001. By 2006, we observe about $75 \%$ of the original sample as being enrolled in a public school in North Carolina. ${ }^{5}$ We an-

\footnotetext{
${ }^{3}$ Relative to national statistics, blacks are overrepresented in North Carolina public elementary and secondary schools (30.4\% vs. $17.2 \%$ nationally) and Hispanics are underrepresented (5.0\% vs. $19.8 \%$ nationally). The percentage of whites in the North Carolina system closely mirrors the national percentage (59.5\% vs. $57.1 \%)$. National data are from the 2007 Digest of Education Statistics, table 40; North Carolina data are from our sample.

${ }^{4}$ IRT is the technique pioneered by the Educational Testing Service and used to create the National Assessment of Educational Progress. It involves measuring skill by simultaneously taking into account the ability of the test taker and various aspects of item characteristics (difficulty, ability to discriminate high and low skill, and guessability). Our test is anchored at grade 3 and recentered at grade 5. The math test was rescaled in 2006. To compute growth scores for the state's accountability system, the North Carolina Department of Public Instruction conducted equating studies to permit conversion of scores across time. These studies, which used equipercentile equating, produced concordance tables to convert old scores to the new metric for the purposes of the state's accountability calculations. This study used these concordance tables to convert scores to a consistent metric.

${ }^{5}$ We retain all students in the cohort regardless of grade retention or promotion status. Students become censored from the sample as a result of leaving the public school system for in-state private schools and schools in different states. Owing to the age of the sample (third-eighth graders), we suspect that very few are school dropouts, but we have no way of verifying dropout status with the data available for this study.
} 
TABLE 1

Descriptive Statistics

\begin{tabular}{|c|c|c|c|c|}
\hline & Mean & $\mathrm{SD}$ & Min & Max \\
\hline \multicolumn{5}{|l|}{ Dependent variables: } \\
\hline Math test score... & 350.78 & 11.84 & 303 & 388 \\
\hline Reading test score. . & 348.04 & 12.89 & 303 & 384 \\
\hline \multicolumn{5}{|l|}{ Student background: } \\
\hline Parent has high school diploma or less . . . . . . . . . & .53 & .42 & 0 & 1 \\
\hline Parent has some postsecondary education . . . . . . . . . & .21 & .41 & 0 & 1 \\
\hline Parent has bachelor's degree or higher . . . . . . . . . & .27 & .44 & 0 & 1 \\
\hline 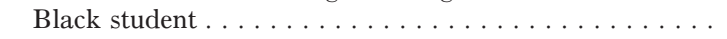 & .30 & .46 & 0 & 1 \\
\hline Hispanic student. . . . . . . . . . . . . . . . & .05 & .22 & 0 & 1 \\
\hline Other racial/ethnic background & .05 & .22 & 0 & 1 \\
\hline Male student. . . . . . . . . . & .50 & .50 & 0 & 1 \\
\hline Student was designated gifted $\ldots \ldots \ldots \ldots \ldots$ & .14 & .35 & 0 & 1 \\
\hline Student received special education services. . . . . . . . & .11 & .32 & 0 & 1 \\
\hline Student showed limited English proficiency & .02 & .15 & 0 & 1 \\
\hline Student was ever retained . . . . . . . . . . & .11 & .32 & 0 & 1 \\
\hline Student received free or reduced-price lunch . . . . . . . . & .45 & .50 & 0 & 1 \\
\hline Student made a structural school move . . . . & .16 & .37 & 0 & 1 \\
\hline Student made a nonstructural school move. . . . . . . . . . . & .09 & .28 & 0 & 1 \\
\hline \multicolumn{5}{|l|}{ Classroom poverty measures: } \\
\hline High-poverty classroom (top quintile) & .24 & .43 & 0 & 1 \\
\hline Cumulative exposure to high-poverty classrooms. . . . . . & .23 & .35 & 0 & 1 \\
\hline Continuous classroom poverty (\% free/reduced lunch)...... & .45 & .26 & 0 & 1 \\
\hline \multicolumn{5}{|l|}{ Time variables: } \\
\hline Grade. . . . . . . & 5.34 & 1.69 & 3 & 8 \\
\hline Grade $^{2} \ldots \ldots \ldots \ldots$ & 31.41 & 18.50 & 9 & 64 \\
\hline
\end{tabular}

NotE.-Observations reported are student-year observations. $N=537,653$.

alyze both reading and math, but to conserve space, we will present descriptive analysis for only the math results. Math scores for students in grades 3-8 range from 303 to 388, with an average of 350.8 and a standard deviation of 11.8 (table 1). By the end of third grade, the average student math score is 339 ; by the end of eighth grade it is 360, suggesting a linear growth rate of about 4.2. This average masks the relatively large increases in the elementary grades (6-7 points per grade) and relatively small increases in middle school grades ( 3 points per grade). To define high-poverty classroom, we begin by standardizing the mean level of a student's classroom peers' free or reduced-price lunch status by grade. Consistent with prior research (Sampson et al. 2008), we dichotomize this variable into a variable coded 1 if a student is in the top quartile of classroom poverty and 0 if a student is in the bottom three quartiles of classroom poverty. ${ }^{6}$ Classroom is defined as

${ }^{6}$ Using an absolute definition of peer poverty - coded 1 if $75 \%$ or more of a student's classroom peers are classified as eligible for free or reduced lunch and 0 otherwise-rather than a relative one does not affect our conclusions about the effect of peer poverty exposure on test score growth (results from authors on request). 
the group of students with whom the student took his or her math test in each year. ${ }^{7}$ Similarly to recent research on neighborhood effects (Jackson and Mare 2007; Crowder and South 2011; Wodtke, Harding, and Elwert 2011), we also derive an alternate measure of classroom poverty designed to better capture cumulative effects, which we call cumulative exposure to a highpoverty classroom. This time-varying variable measures the proportion of years up to and including the current year a student has attended a highpoverty classroom: $\sum_{t=1}^{T} \mathrm{HPC}_{t i} / T$. Thus, a student can be coded only 0 or 1 during third grade but can be coded $0,0.5$, or 1 during fourth grade. An eighth grader coded as 0 was never exposed to a high-poverty classroom, while one coded as 1 was always exposed to high-poverty classrooms. Descriptive statistics in table 1 indicate that, on average, students in our cohort spend $24 \%$ of their third- through eighth-grade years in high-poverty classrooms. About half of eighth graders were never exposed to a high-poverty classroom; only $5 \%$ of eighth graders were always exposed. Since we would expect the effect of the contrast between never exposed and always exposed to be larger than the contrast between high- and low-poverty classroom at one point in time, the cumulative exposure measure provides perhaps the strongest possible test of the contextual effects hypothesis with longitudinal data. To be consistent with research using a continuous measure, we also report results from the classroom percentage eligible for a free or reducedprice lunch. For ease of exposition, below we will refer generically to the construct of classroom poverty to encompass all three measures, distinguishing among them when needed.

Classroom poverty is time varying rather than fixed because (1) students can be assigned to classrooms with varying poverty composition over time, (2) students change schools as a result of residential changes and school choice, and (3) students make structural school enrollment changes (i.e., those arising from policy-induced school mobility due to how grade configurations are structured, chiefly changing from an elementary to a middle school, rather than family choices). Measuring classroom poverty at the classroom rather than at the school level permits within-school variation in classroom poverty to contribute to estimates. There is considerable variation in classroom poverty both within and between schools. School average classroom poverty rates range from $0 \%$ to $100 \%$, with an average of $50 \%$ and a standard deviation of $24 \%$. About $75 \%$ of total variation in classroom poverty rates lies between elementary schools, while $25 \%$ of variation is between classrooms within schools. Perhaps because of early tracking, the portion of variation that lies between classrooms in middle schools is larger, at $40 \%$, leaving $60 \%$ between schools.

${ }^{7}$ Classrooms with five or fewer students (less than $2 \%$ of the student-year observations) were dropped from the analysis. 
Control variables available for this study are race or ethnicity, gender, family poverty status, and parental education; educational designations as gifted, special education, or limited English proficient; whether the student was ever retained in a grade; and structural and nonstructural school transitions. Family poverty (free or reduced lunch eligibility) is a time-varying covariate because student free and reduced-price lunch eligibility changes from year to year as a result of changes in family income. For the population used in this study, the family poverty level of the student changes at least once for about $15 \%$ of the students. School mobility is separated into structural and nonstructural measures based on whether a school switch was mandated by school district policy (a structural move such as moving from elementary to middle school) or was a result of family choice or residential mobility (a nonstructural move). We impute missing values for covariates at time $t$ by assigning the subject-specific panel average. For example, if a student has a missing value in his or her panel of the family poverty indicator, we impute the average of that student's family poverty indicators across the other panels. For the dependent variable, math test score, we drop subjects whose panels contain less than half nonmissing scores and then impute with the grade-level average of students who were ever missing, since students who were ever missing had lower test scores than those who were never missing. A table of means before and after imputation for analysis variables is shown in the appendix (table A1).

\section{METHODS}

\section{Cross-Sectional Model}

To reproduce cross-sectional estimates commonly reported in previous research, we begin by presenting point-in-time estimates of the association of classroom poverty on student achievement from a multilevel model (students nested within classrooms). We model math achievement, $A$, for student $i$ in classroom $j$ as a function of classroom poverty, $Z$, and $\mathbf{X}$, a vector of student covariates that includes the student's own family poverty status:

$$
A_{i j}=\beta_{0}+\beta_{1} Z_{i}+\gamma \mathbf{X}_{i t}+u_{0 j}+\varepsilon_{i j}
$$

In (1), we include a random intercept for each classroom, $u_{0 j}$, and estimate (1) by grade level to examine whether the effect of classroom poverty varies by grade. The classroom poverty estimate from (1) could be considered causal if $\mathbf{X}$ contains all confounders of the effect of $Z$ on $A$, if these confounders are measured without error, and if the random effects are uncorrelated with each other and the covariates in the model. These conditions would apply if $E\left(u_{0 i} \mid Z_{i}\right)=0$ and $E\left(\varepsilon_{i j} \mid Z, \mathbf{X}_{i j}, u_{0 i}\right)=0$. For example, 
many contextual effects studies, including the present one, have no or poorly measured information about the quality of students' early childhood education. If students with high-quality early childhood education experiences are less likely to enroll in high-poverty classrooms, we would expect $\beta_{1}$ to be downwardly biased; that is, if we controlled for the quality of early childhood education, the hypothesized negative effect of attending a high-poverty classroom would be closer to zero than the unadjusted estimate.

\section{Growth Model}

Using test score data that are interval scaled and vertically equated to allow for growth modeling, we estimate a quadratic growth model with random intercept and slopes. Researchers in sociology, psychology, education, and criminology often use multilevel methods to account for within-subject intercorrelation, a wide range of covariance structures, and empirical Bayes estimation, which weights estimates by their reliability (the ratio of the true score variance to the observed score variance; Bryk and Raudenbush 1987; Singer and Willett 2003). We formulate our quadratic growth model as

$$
\begin{aligned}
A_{t i}= & \beta_{0}+\beta_{1} \operatorname{Grade}_{t i}+\beta_{2} \operatorname{Grade}_{t i}^{2}+\beta_{3} Z_{t i}+\theta \mathbf{X} \mathbf{T}_{t i}+\gamma \mathbf{X}_{i}+u_{0 i} \\
& +u_{1 j} \text { Grade }_{t i}+u_{2 j} \operatorname{Grade}_{t i}^{2}+u_{3 i} Z_{t i}+\varepsilon_{t i} .
\end{aligned}
$$

This model regresses a math achievement test score, $A$, at time $t$ for student $i$ on grade level, grade squared, a classroom poverty indicator, a vector of time-varying covariates, $\mathbf{X T}$, and a vector of time-invariant covariates, $\mathbf{X}$, with all covariates grand mean centered. Owing to the problem of timevarying confounding, we omit from XT variables that could be affected by prior treatment status such as school mobility and assignment to gifted, special education status, limited English proficiency, or grade retention. The model allows the intercept and slopes of Grade, Grade ${ }^{2}$, and $Z$ to randomly vary, and the variance-covariance matrix, $\Sigma$, imposes no restrictions on the covariation of these random effects (i.e., the matrix is specified as unstructured). We also estimate a model that interacts variables in $\mathbf{X}$ and $\mathbf{X T}$ with Grade and Grade ${ }^{2}$ to ensure that our estimates are not biased by differential growth rates across different subpopulations of students.

Random-effects models such as the growth model shown in equation (2) produce a precision-weighted least-squares estimate that depends on within- and between-student variance components ( $\sigma_{e}^{2}$ and $\sigma_{u}^{2}$, respectively) and the average number of periods per student $(\bar{T})$. In a generic panel regression of $y$ on $x$, both sides of the equation are quasi-demeaned with a weighting parameter, $\lambda$ : 
American Journal of Sociology

$$
\left(y_{i t}-\lambda \bar{y}_{i}\right)=\beta_{0}(1-\lambda)+\beta_{1}\left(x_{i t}-\lambda \bar{x}_{i}\right)+\left(e_{i t}-\lambda \bar{e}_{i}\right)
$$

where

$$
\lambda=1-\sqrt{\frac{\sigma_{e}^{2}}{\sigma_{u}^{2}+T \sigma_{e}^{2}}} .
$$

As $\sigma_{e}^{2} \rightarrow 0, \lambda \rightarrow 1$, the random-effects estimate converges toward the fixed-effects estimate (discussed below). As $\sigma_{u}^{2} \rightarrow 0, \lambda \rightarrow 1$, the randomeffects estimate converges toward the pooled ordinary least squares (OLS) estimate (Wooldridge 2003). Typically $0<\lambda<1$, with the random-effects estimate falling between the pooled OLS and the fixed-effect estimates.

The coefficient of interest in this model is $\beta_{3}$, the average effect of classroom poverty on achievement across grades 3-8. Parameters estimated with model (2) are unbiased and efficient assuming that, given the covariates, the random effects, and the student-level residual, $\varepsilon_{t i}$, are normally distributed with zero mean, are independent of one another, with the random effect independent across subjects and $\varepsilon_{t i}$ independent across subjects and occasions. ${ }^{8}$ The growth model produces an unbiased estimate of the effect of classroom poverty on test score growth if classroom poverty is uncorrelated with the random effects, if $Z$ and the variables in XT are exogenous, and if family background is adequately controlled and well measured. ${ }^{9}$

As with the cross-sectional model, omitted variable bias could produce inconsistent parameter estimates, which could threaten the validity of this model. Although multilevel models can increase efficiency because of the use of both within and between variance, such models provide no solution for this type of confounding bias. If the between-student effects of classroom

\footnotetext{
${ }^{8}$ We specify growth models as two-level models, occasions within subjects, rather than occasions nested within subjects cross-nested in classrooms because of computational limitations, our focus on the parameter estimates rather than the random effects, and the fact that with population-level data, efficient estimates of standard errors are a secondary concern. Moreover, simulation evidence suggests that ignoring cross-nesting is likely to affect the variance components and not the parameter estimates (see Luo and Kwok 2009).

${ }^{9}$ In studies of peer achievement effects but not classroom poverty effects, the direction of causality may be quite difficult to determine because student achievement at time $t$ and peer achievement at time $t$ are simultaneously determined (see Manski 1993). Determining the causal direction between classroom poverty and achievement is more straightforward. We posit that classroom poverty affects student achievement and that student achievement at time $t$ does not affect classroom poverty at time $t$. This seems like a reasonable assumption given that students' academic performance has no bearing on their parents' earning power.
} 
poverty are large relative to the within-student effects, it is possible that the omission of student and family background characteristics could bias estimates of classroom poverty contextual effects. In thinking about bias, it is helpful to return to our explanations of classroom poverty effects: contagion, relative deprivation, collective socialization, and institutions. Classroom effects can emerge either because students affect each other or because adults in schools affect students. The former pertains to contagion and relative deprivation explanations; the latter pertains to an institutional or collective socialization explanation. In either case, the validity of inferences about contagion or institutional effects depends on removing the confounding effects of student and family background. We address the threat of adverse selection based on time-invariant family and student background characteristics with a student fixed-effects specification.

\section{Student Fixed-Effects Model}

We estimate a student fixed-effects model to control for fixed unobservables such as innate ability, mother's IQ, and early childhood experiences that might confound the effect of classroom poverty on test score. The fixedeffects formulation uses each student as his or her own baseline, which holds constant all observable, unobservable, and mismeasured time-invariant student and family background characteristics. This approach eliminates all time-invariant between-student confounding in the classroom poverty effect and produces consistent parameter estimates when there is no within-student confounding of the classroom poverty effect. The student fixed-effects model is specified as

$$
A_{t i}=\beta_{0}+\beta_{1} \text { Grade }_{t i}+\beta_{2} \operatorname{Grade}_{t i}^{2}+\beta_{3} Z_{t i}+\theta \mathbf{X T}_{t i}+\alpha_{i}+\varepsilon_{t i} .
$$

Here we treat the subject-specific intercept as a fixed unknown parameter to be estimated, with $\alpha_{i}$ representing the deviation of subject $i$ 's intercept from the mean intercept $\beta_{0}$ with $\sum_{i}^{I} \alpha_{i}=0$. This model is often estimated by "demeaning" both sides of the equation by the subject's panel mean, which removes between-student confounding by using only withinsubject variation to estimate parameters. Omitted from equation (5) are time-invariant covariates because these have no within-subject variance and are therefore not estimable with this approach (though their effects are subsumed into the subject-specific intercept).

The student fixed-effects approach requires within-student variation on classroom poverty to identify parameters and is relatively inefficient relative to the random-effects models. Because of its large sample size and the six-year panels within it, however, our data are well suited to this approach. We identify the classroom poverty effect from year-to-year varia- 
tion in the poverty composition of students' classrooms. This changes as a result of school mobility and variations in the poverty compositions of students' assigned classrooms as they progress through grade levels in the same school. Because classroom poverty rates vary more between schools than within schools, school movers are somewhat more likely to experience a change in classroom poverty than students who remain in the same school. Nearly the entire sample makes some sort of school move during their panel: $85 \%$ of students make a structural move (e.g., moving from elementary to middle school), $35 \%$ of students make a nonstructural move (e.g., moving as a result of residential mobility), and $91 \%$ of students make either a structural move or a nonstructural move or both. The evidence suggests that across time, variation exists to analyze both school stayers and school movers but that a larger portion of the variation that is analyzed appears to come from movers.

In total, about two-thirds of students move either into or out of a highpoverty classroom at least once during their panel. About $17 \%$ of students make a change into or out of a high-poverty classroom during the third to fourth, fourth to fifth, sixth to seventh, or seventh to eighth grade transitions, whereas $20 \%$ of students make one of these changes during the fifth to sixth grade transition (a shift from elementary to middle school for most students in the sample). These changes are evenly split: $52 \%$ are changes into a high-poverty classroom and $48 \%$ are changes out of a high-poverty classroom. On average, the changes into a high-poverty classroom are a grade-to-grade increase of $22 \%$ in peer poverty and the changes out of a high-poverty classroom are a grade-to-grade decrease of $28 \%$ in peer poverty. Students who do not change on the binary high-poverty classroom variable on average have a grade-to-grade decrease of $1.4 \%$ in peer poverty.

Estimates from model (5) can be considered causal assuming that selection into high-poverty classrooms is based only on time-invariant unobservables. The model does not adjust for unobserved time-varying exogenous factors that could be related to attending a high-poverty classroom. We must assume strict exogeneity, that for each $t$, the expected value of the idiosyncratic error given the explanatory variables in all time periods and the student fixed effect is zero: $E\left(\varepsilon_{t i} \mid \mathbf{X}_{i}, \alpha_{i}\right)=0$, where $\mathbf{X}$ is a vector containing all variables appearing on the right-hand side of equation (5).

\section{Marginal Structural Model}

Both the multilevel and fixed-effects models outlined above are vulnerable to the threat of time-varying confounding, which arises when there is a timevarying variable that is affected by prior treatment and is associated with subsequent treatment and the outcome. For example, consider the causal diagram in figure 1 . In this diagram, $X$ is a time-varying control variable, $Z$ is 


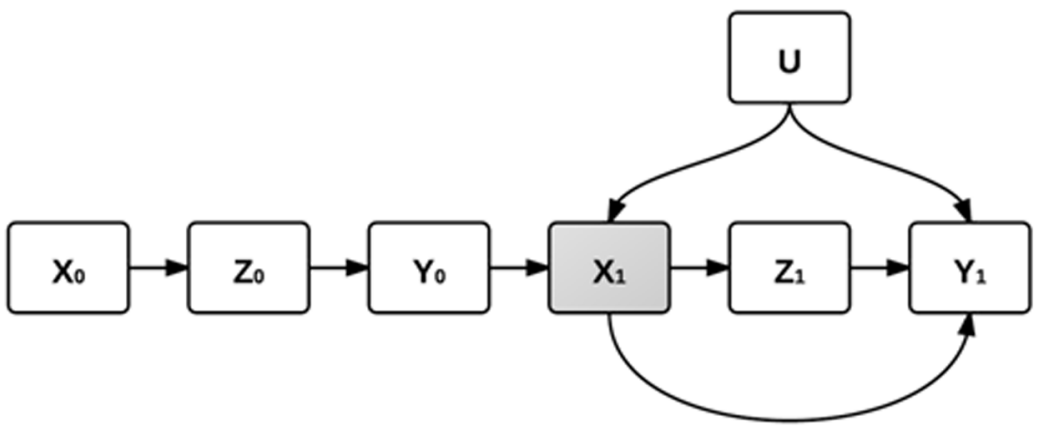

Fig. 1.-Causal diagram showing a time-varying confounder $\left(X_{1}\right)$ on the causal pathway between treatment occasions and the outcome.

treatment (high-poverty classroom), $Y$ is outcome (test score achievement), the subscript 0 represents baseline variables and 1 the subsequent time period variables, and $U$ is an unobservable that affects both $X_{1}$ and $Y_{1}$. The variable in the shaded box, $X_{1}$, is a time-varying confounder (e.g., assignment to gifted or special education) because it predicts future treatment, $Z_{1}$, and is associated with future outcome, $Y_{1}$, via $U$ and directly (Robins et al. 2000). Because $X_{1}$ is affected by prior treatment through the prior outcome (i.e., endogenous), standard models will produce biased treatment effect estimates.

Time-varying confounding presents a dilemma: $X_{1}$ is a confounder for later treatment and thus must be controlled, but it may also be affected by earlier treatment and thus cannot be controlled (Robins et al. 2000). Because $X_{1}$ is a collider (it is an effect of both $Y_{0}$ and $U$ ), controlling for $X_{1}$ introduces collider stratification bias (Greenland 2003; Hernán, HernándezDíaz, and Robins 2004; Cole et al. 2010). An MSM fit using IPTW can account for time-varying confounding and produce asymptotically consistent estimates of treatment effects in longitudinal analysis. This approach involves first computing IPT weights from each subject's probability of having his or her own treatment history and, second, estimating an IPT-weighted regression model. Our MSM is a weighted version of the growth model shown in equation (2).

Following standard practice, we compute stabilized weights that have lower variance than nonstabilized weights (Robins et al. 2000):

$$
\mathrm{IPTW}_{t i}=\prod_{k=0}^{t} \frac{P\left[Z_{k}=z \mid Z_{k-1}, Z_{0}, Y_{0}, \mathbf{X}_{0}, G_{k}\right]}{P\left[Z_{k}=z \mid Z_{k-1}, Z_{0}, Y_{k-1}, Y_{0}, \mathbf{X}_{k-1}, \mathbf{X}_{0}, G_{k}\right]},
$$

where $t$ indexes time, $i$ indexes student, $Z_{k}=z$ is treatment actually received (classroom poverty exposure), $Y$ is outcome, $\mathbf{X}$ is a vector of time-invariant 
and time-dependent confounds, and $G$ is grade level; variables subscripted with a 0 represent baseline values and variables subscripted with $k-1$ are one-period lags. In $\mathbf{X}$ we include student background characteristics (race or ethnicity, gender, family poverty status, parental education), school mobility variables, and academic classifications (gifted, special education, limited English proficiency, and grade retention). The denominator is, informally, a student's conditional probability of receiving her own observed treatment up to time $t$, given past treatment, outcome, covariate history, and grade level. The numerator is, informally, a student's conditional probability of receiving her own observed treatment up to time $t$, given past treatment, baseline outcome, baseline covariates, and grade level. This technique is a generalization of propensity score methods for longitudinal data. Rather than weighting inversely proportional to the probability of receiving treatment $(Z=1)$, we instead weight inversely proportional to the probability of the treatment status actually received $(Z=z)$. We truncate weights at the 1 st and 99 th percentiles by recoding observations above the 99 th percentile to the 99th percentile weight and recoding observations below the 1st percentile to the 1st percentile weight (Cole and Hernán 2008).

Our MSM models also adjust for possible bias due to selective attrition (Herńan et al. 2000). We compute a stabilized censoring weight as

$$
\mathrm{CW}_{t i}=\prod_{k=0}^{t} \frac{P\left[C_{k}=0 \mid C_{k-1}=0, Z_{k}, Z_{k-1}, Z_{0}, Y_{0}, \mathbf{X}_{0}, G_{k}\right]}{P\left[C_{k}=0 \mid C_{k-1}=0, Z_{k}, Z_{k-1}, Z_{0}, Y_{k-1}, Y_{0}, \mathbf{X}_{k-1}, \mathbf{X}_{0}, G_{k}\right]}
$$

where $t, i, Z, Y, \mathbf{X}$, and $G$ are defined above, and $C_{k}$ is an indicator that the student became censored at time $t$ (i.e., the last observation in the student's panel). To adjust for both the inverse of the probability of treatment and censoring, the weight used in the MSM models is the product of the IPT and censoring weights $\left(\mathrm{IPTW}_{t i} \times \mathrm{CW}_{t i}\right)$.

The IPT-weighted version of the model shown in equation (2) produces a consistent estimate of treatment effect under the assumption of no unmeasured confounders or sequential strong ignorability (that treatment assignment is conditionally independent of the current and future potential outcomes given the measured past).

\section{RESULTS}

We begin by discussing descriptive analysis of the difference in the medians and distribution of test scores by grade and classroom poverty composition. We then summarize results from cross-sectional models that show substantial associations between classroom poverty and student test score, especially in the middle school grades. Following this, we present random co- 


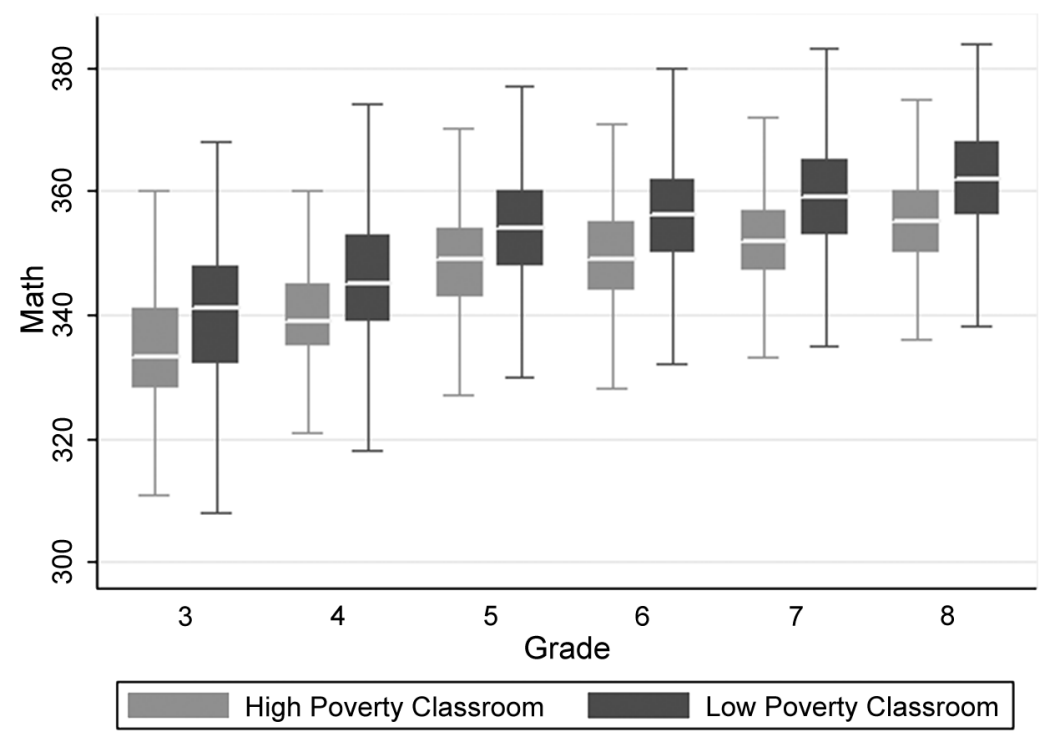

FIG. 2.-Math score by classroom poverty and grade. Each box contains the 25 th75 th percentile, with the white line in each box at the median. Whiskers indicate the 5 th and 95 th percentiles.

efficient growth model estimates and two alternative specifications with student fixed effects and IPTW for our three measures of classroom poverty: exposure to a high-poverty classroom, cumulative exposure, and continuous classroom poverty. We then present a summary table of effect sizes and confidence intervals for all results.

Figure 2 displays a box plot of the distribution of math test scores by grade level and the high-poverty classroom measure. The plot shows a general upward trend in scores and a reduction in the interquartile range for both groups as students increase in grade level. The gap in median test scores between students in high- and low-poverty classrooms in third grade is 6 points; by eighth grade it is 7 points. The slight widening of the gap is more noticeable among eight graders always and never exposed to a highpoverty classroom (the cumulative exposure measure), with the gap in median test scores growing from 6 points to 10 points between third and eighth grade (results not shown but available from the authors on request).

Cross-Sectional Estimates of Classroom Poverty and Cumulative Exposure

We produce cross-sectional estimates from the students-within-classrooms multilevel random intercept model shown in equation (1), which control for 


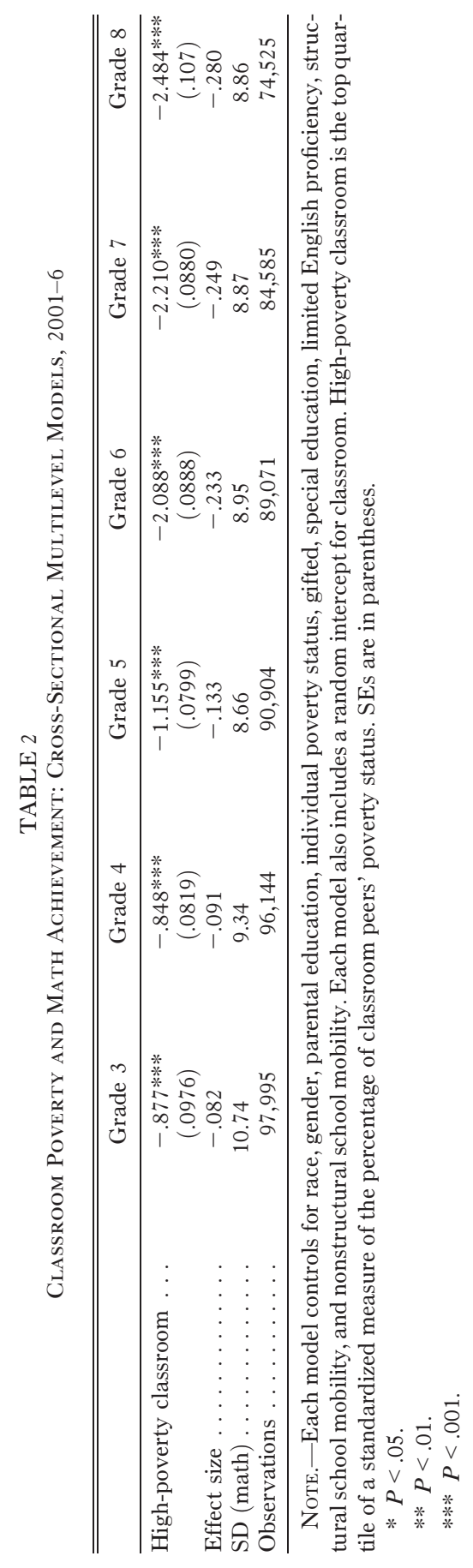


(but do not display) race, gender, parental education, family poverty status, gifted, special education, limited English proficiency status, grade retention, and structural and nonstructural school mobility. We estimate models separately by grade level. As seen in table 2, net of controls, the third-grade cross-sectional effect of attending a high-poverty classroom is -.877 scale points, or a standardized effect size of $-.082 \sigma(-.877 / 10.74=.082)$. Between fifth and sixth grade, this effect jumps from $-.133 \sigma$ to $-.233 \sigma$. By eighth grade this estimate has grown to $-.280 \sigma$. If causal, these results could reflect the differentiation of math curriculum in middle school (Hallinan 1992; Dauber, Alexander, and Entwisle 1996) and the growing influence of peers for young adolescents (Furman 1982; Buchmann and Dalton 2002; Veronneau and Dishion 2011) or the cumulative nature of cognitive disadvantage through the life course of children and young adolescents. Replacing the high-poverty classroom variable in equation (1) with the our cumulative exposure variable produces even larger point estimates, with the estimate growing from $-.082 \sigma$ to $-.429 \sigma$ between third and eighth grade (not shown but results available from the authors on request). In summary, we find substantively large cross-sectional associations of high-poverty classroom and cumulative exposure to high-poverty classrooms that increase with grade level and become especially large by eighth grade, suggesting that test score trajectories may widen over time between students exposed to higher-versus lower-poverty classrooms. As we have argued above, however, a growth model is a more appropriate model to estimate the gap between higher- and lower-poverty classrooms than a cross-sectional one. A random-coefficients growth model produces precision-weighted trajectories, which provide much more convincing evidence of the effect of context on student achievement than a point-in-time estimate.

\section{Growth Model Estimates of High-Poverty Classroom}

Table 3 displays coefficients from time-nested within-student randomcoefficient growth models for math (see eq. [2] above). ${ }^{10}$ Column 1 shows an unadjusted effect of high-poverty classroom of -2.249 . Including Grade and $\mathrm{Grade}^{2}$ reduces the classroom poverty effect by about $70 \%$. The coefficient shrinks from -2.249 to -.683 because including grade level (a withinstudent parameter) greatly reduces unexplained within-student variation $\left(\sigma_{e}\right)$ while leaving between-student variation $\left(\sigma_{u}\right)$ essentially unchanged. As discussed above, when within-student variation falls between models 1 and $2, \lambda$ increases, which pulls the classroom poverty effect closer to the fixedeffect estimate, which, as we will see below, is quite close to zero. At the

\footnotetext{
${ }^{10}$ Alternative models using age instead of grade produce similar results (available from the authors on request).
} 
TABLE 3

Classroom Poverty and Math Achievement: Random-Coefficient Growth Models, 2001-6

\begin{tabular}{|c|c|c|c|c|}
\hline & $\begin{array}{c}\text { Classroom } \\
\text { Poverty } \\
(1)\end{array}$ & $\begin{array}{l}\text { With Growth } \\
\text { (2) }\end{array}$ & $\begin{array}{c}\text { With Student } \\
\text { Characteristics } \\
\text { (3) }\end{array}$ & $\begin{array}{c}\text { With Student } \\
\text { Characteristics } \\
\text { Interactions } \\
\text { (4) }\end{array}$ \\
\hline \multicolumn{5}{|l|}{ High-poverty } \\
\hline classroom . . . . . . & $\begin{array}{c}-2.249 * * * \\
(.0413)\end{array}$ & $\begin{array}{l}-.683 * * * \\
(.0191)\end{array}$ & $\begin{array}{l}-.413 * * * \\
(.0191)\end{array}$ & $\begin{array}{l}-.407 * * * \\
(.0191)\end{array}$ \\
\hline Grade . . . . . . . . . & & $\begin{array}{c}4.166 * * * \\
(.00451)\end{array}$ & $\begin{array}{c}4.148 * * * \\
(.00453)\end{array}$ & $\begin{array}{l}4.142 * * * \\
(.00451)\end{array}$ \\
\hline Grade $^{2} \ldots \ldots \ldots \ldots$ & & $-.651 * * * 1$ & $\begin{array}{l}-.651 * * * \\
(.00229)\end{array}$ & $\begin{aligned}-.653 * * * \\
(.00229)\end{aligned}$ \\
\hline \multicolumn{4}{|l|}{$\begin{array}{l}\text { Parent has some } \\
\text { postsecondary }\end{array}$} & $\begin{array}{l}.419 * * * \\
(.0230)\end{array}$ \\
\hline $\begin{array}{l}\text { Parent has bachelor's } \\
\text { degree or more ..... }\end{array}$ & & & $\begin{array}{l}1.057 * * * \\
(.0217)\end{array}$ & $\begin{array}{l}.764 * * * \\
(.0265)\end{array}$ \\
\hline Black. . . . . . . . . . & & & $\begin{array}{c}-6.324 * * * \\
(.0523)\end{array}$ & $\begin{array}{c}-6.358 * * * \\
(.0538)\end{array}$ \\
\hline Hispanic . . . . . . . . & & & $\begin{array}{c}-3.507 * * * \\
(.108)\end{array}$ & $\begin{array}{c}-3.661 * * * \\
(.111)\end{array}$ \\
\hline Other race/ethnicity ... & & & $\begin{array}{c}-1.313 * * * \\
(.120)\end{array}$ & $\begin{array}{c}-1.454^{* * *} * \\
(.122)\end{array}$ \\
\hline Male $\ldots \ldots \ldots \ldots$ & & & $\begin{array}{l}-.419^{* * * *} \\
(.0480)\end{array}$ & $\begin{array}{l}-.302 * * * \\
(.0490)\end{array}$ \\
\hline Student poverty . . . . . & & & $\begin{array}{l}-.706 * * * \\
(.0236)\end{array}$ & $\begin{array}{l}-.601 * * * \\
(.0275)\end{array}$ \\
\hline Constant $\ldots \ldots \ldots \ldots$ & $\begin{array}{r}350.2 * * * \\
(.0283)\end{array}$ & $\begin{array}{r}352.5 * * * \\
(.0269)\end{array}$ & $\begin{array}{r}352.5 * * * \\
(.0243)\end{array}$ & $\begin{array}{r}352.5 * * * \\
(.0245)\end{array}$ \\
\hline$\sigma_{u} \ldots \ldots \ldots \ldots$ & $\begin{array}{l}7.809 * * * \\
(.370)\end{array}$ & $\begin{array}{l}7.968 * * * \\
(.322)\end{array}$ & $\begin{array}{l}7.118 * * * \\
(.268)\end{array}$ & $\begin{array}{l}7.175^{* * * *} \\
(.274)\end{array}$ \\
\hline$\sigma_{e} \ldots \ldots \ldots \ldots \ldots$ & $\begin{array}{l}8.461 * * * \\
(.160)\end{array}$ & $\begin{array}{l}3.722 * * * \\
(.0392)\end{array}$ & $\begin{array}{l}3.736 * * * \\
(.0397)\end{array}$ & $\begin{array}{l}3.733 * * * \\
(.0396)\end{array}$ \\
\hline $\mathrm{SD}$ (high-poverty & & & & \\
\hline classrom) $\ldots \ldots \ldots$ & $\begin{array}{l}5.596 * * * \\
(.666)\end{array}$ & $\begin{array}{l}1.027 * * * \\
(.116)\end{array}$ & $\begin{array}{l}.930 * * * \\
(.114)\end{array}$ & $\begin{array}{l}.907 * * * \\
(.112)\end{array}$ \\
\hline $\mathrm{SD}($ grade $) \ldots \ldots \ldots$ & & $\begin{array}{l}.978 * * * \\
(.00906)\end{array}$ & $\begin{array}{l}.976 * * * \\
(.00906)\end{array}$ & $\begin{array}{l}.955 * * * \\
(.00888)\end{array}$ \\
\hline $\mathrm{SD}\left(\operatorname{grade}^{2}\right) \ldots$ & & $\begin{array}{l}.279 * * * \\
(.00251)\end{array}$ & $\begin{array}{l}.280 * * * \\
(.00252)\end{array}$ & $\begin{array}{l}.257 * * * \\
(.00246)\end{array}$ \\
\hline Observations ....... & 537,653 & 537,653 & 537,653 & 537,653 \\
\hline
\end{tabular}

Note.-Random-coefficient models (see eq. [2]) with an unstructured covariance matrix. Covariances of random effects are not shown. Model 4 includes interactions between listed student background controls and grade and grade ${ }^{2}$ (coefficients not shown). Robust SEs are in parentheses.

$$
\begin{aligned}
& * P<.05 . \\
& * * P<.01 . \\
& * * * P<.001 .
\end{aligned}
$$


TABLE 4

Classroom Poverty and Reading Achievement: Random-Coefficient Growth Models, 2001-6

\begin{tabular}{|c|c|c|c|c|}
\hline & $\begin{array}{l}\text { Classroom } \\
\text { Poverty } \\
(1)\end{array}$ & $\begin{array}{l}\text { With Growth } \\
\text { (2) }\end{array}$ & $\begin{array}{c}\text { With Student } \\
\text { Characteristics } \\
(3)\end{array}$ & $\begin{array}{c}\text { With Student } \\
\text { Characteristics } \\
\text { Interactions } \\
\text { (4) }\end{array}$ \\
\hline \multicolumn{5}{|l|}{ High-poverty } \\
\hline classroom. . . . . . . . & $\begin{array}{c}-2.275 * * * \\
(.0469)\end{array}$ & $\begin{array}{l}-.727 * * * \\
(.0220)\end{array}$ & $\begin{array}{l}-.418 * * * \\
(.0221)\end{array}$ & $\begin{array}{l}-.399 * * * \\
(.0220)\end{array}$ \\
\hline Grade $\ldots \ldots \ldots \ldots$ & & $\begin{array}{l}4.656 * * * \\
(.00517)\end{array}$ & $\begin{array}{l}4.631 * * * \\
(.00520)\end{array}$ & $\begin{array}{l}4.630 * * * \\
(.00513)\end{array}$ \\
\hline Grade $^{2} \ldots$ & & $\begin{array}{l}-.570 * * * \\
(.00260)\end{array}$ & $\begin{array}{c}-.573 * * * \\
(.00261)\end{array}$ & $\begin{array}{c}-.570 * * * \\
(.00263)\end{array}$ \\
\hline \multicolumn{5}{|l|}{$\begin{array}{l}\text { Parent has some } \\
\text { postsecondary }\end{array}$} \\
\hline $\begin{array}{l}\text { Parent has bachelor's } \\
\text { degree or more. . . . . . }\end{array}$ & & & $\begin{array}{l}1.278 * * * \\
(.0248)\end{array}$ & $\begin{array}{l}1.145 * * * \\
(.0311)\end{array}$ \\
\hline Black. . . . . . . . . . . & & & $\begin{array}{c}-6.097 * * * \\
(.0550)\end{array}$ & $\begin{array}{c}-6.662 * * * \\
(.0591)\end{array}$ \\
\hline Hispanic . . . . . . . . . & & & $\begin{array}{c}-3.905 * * * \\
(.116)\end{array}$ & $\begin{array}{c}-5.074 * * * \\
(.123)\end{array}$ \\
\hline Other race/ethnicity ... & & & $\begin{array}{c}-1.769^{* * *} \\
(.115)\end{array}$ & $\begin{array}{c}-2.392 * * * \\
(.124)\end{array}$ \\
\hline Male . . . . . . . . . & & & $\begin{array}{c}-1.617^{* * *} * \\
(.0481)\end{array}$ & $\begin{aligned} &-1.702 * * * \\
&(.0519)\end{aligned}$ \\
\hline Student poverty . . . . . & & & $\begin{array}{l}-.951 * * * \\
(.0271)\end{array}$ & $\begin{array}{l}-.869 * * * \\
(.0325)\end{array}$ \\
\hline Constant . . . . . . . & $\begin{array}{r}347.5 * * * \\
(.0303)\end{array}$ & $\begin{array}{r}349.6 * * * \\
(.0290)\end{array}$ & $\begin{aligned} 349.6 * * * \\
(.0259)\end{aligned}$ & $\begin{aligned} 349.6 * * * \\
(.0260)\end{aligned}$ \\
\hline$\sigma_{u} \ldots \ldots \ldots \ldots$ & $\begin{array}{l}8.237 * * * \\
(.425)\end{array}$ & $\begin{array}{l}8.479 * * * \\
(.373)\end{array}$ & $\begin{array}{l}7.460 * * * \\
(.305)\end{array}$ & $\begin{array}{l}7.483 * * * \\
(.310)\end{array}$ \\
\hline$\sigma_{e} \ldots \ldots \ldots \ldots \ldots$ & $\begin{array}{l}9.481^{* * * *} \\
(.201)\end{array}$ & $\begin{array}{l}4.448 * * * \\
(.0556)\end{array}$ & $\begin{array}{l}4.466 * * * \\
(.0563)\end{array}$ & $\begin{array}{l}4.465 * * * \\
(.0562)\end{array}$ \\
\hline $\mathrm{SD}$ (high-poverty & & & & \\
\hline classroom) ... & $\begin{array}{l}6.407 * * * \\
(.829)\end{array}$ & $\begin{array}{l}1.206 * * * \\
(.153)\end{array}$ & $\begin{array}{l}1.086^{* * * *} \\
(.150)\end{array}$ & $\begin{array}{l}1.095 * * * \\
(.150)\end{array}$ \\
\hline $\mathrm{SD}$ (grade) . . & & $\begin{array}{l}1.103 * * * \\
(.0121)\end{array}$ & $\begin{array}{l}1.097 * * * \\
(.0121)\end{array}$ & $\begin{array}{l}1.052 * * * \\
(.0117)\end{array}$ \\
\hline $\mathrm{SD}\left(\operatorname{grade}^{2}\right) \ldots$ & & $\begin{array}{l}.247 * * * \\
(.00331)\end{array}$ & $\begin{array}{l}.247 * * * \\
(.00333)\end{array}$ & $\begin{array}{l}.237 * * * \\
(.00331)\end{array}$ \\
\hline Observations ....... & 537,653 & 537,653 & 537,653 & 537,653 \\
\hline
\end{tabular}

Note.- Random-coefficient models (see eq. [2]) with an unstructured covariance matrix. Covariances of random effects are not shown. Model 4 includes interactions between listed student background controls and grade and grade ${ }^{2}$ (coefficients not shown). Robust SEs are in parentheses.

$$
\begin{aligned}
& * P<.05 . \\
& * * P<.01 . \\
& * * * P<.001 .
\end{aligned}
$$


average of grade, the average student has a math test score of 352.5 , an instantaneous growth rate of 4.166, and a negative curvature parameter of -0.651 , which indicates that students' rate of change in test score growth declines over time. Including covariates in column 3 further reduces the classroom poverty effect from -0.683 to -0.413 , suggesting that the classroom poverty effect is due in part to compositional differences across classrooms. Most control variable coefficients conform to expectations, with negative effects for minorities, males, and poor students and positive differences for students with highly educated parents. The classroom poverty effect indicates that the predicted gap between students in high- and lowpoverty classrooms across grades $3-8$ is -0.413 scale points, or $.035 \sigma$. In column 4, we include interactions between all student background controls and Grade and Grade ${ }^{2}$. Allowing the effects of student background to vary with grade level does not significantly alter our treatment effect estimate. Table 4 shows these same models with reading test score as the outcome. Similarly to the effects on math, the coefficient drops from -2.275 scale points in the unadjusted model to -0.399 scale points $(.031 \sigma)$ in the fourth model.

Fixed-Effect and MSM Growth Model Estimates of High-Poverty Classroom

Growth model estimates are unbiased assuming that all confounders are controlled. A student fixed-effects model controls for fixed prebaseline unobservables such as innate ability, early childhood experiences, and mother's IQ that might confound the effect of classroom poverty on test scores. By using only within-student variation in classroom poverty, this approach eliminates all time-invariant between-student confounding and produces unbiased parameter estimates when all time-varying confounders are controlled. The strength of the student fixed-effects model is adjustment for time-invariant unobservables. A weakness of both the growth model and the student fixed-effects specification is that neither appropriately adjusts for time-dependent confounding. An MSM with IPTW is designed to address time-dependent confounding. Table 5 presents in column 1 estimates from the primary coefficients of interest from the random-effects growth model shown in model 3 of tables 3 and 4, student fixed-effects estimates in column 2 (see eq. [5]), and MSM with IPTW estimates in column 3 (the random-effects growth model in col. 1 estimated with the weights computed by eqq. [6] and [7]).

In both math and reading, the absolute values of the student fixed-effects estimates and the MSM estimates are much smaller than the randomcoefficients estimates. The effect of high-poverty classroom on math in the MSM model is not statistically different from zero, and the effect on reading is significant only at the $P<.05$ level. Both of these alternative specifica- 
TABLE 5

High-Poverty Classroom and Achievement: Comparison of Alternative Specifications, 2001-6

\begin{tabular}{|c|c|c|c|}
\hline & $\begin{array}{c}\text { Random } \\
\text { Coefficients } \\
(1)\end{array}$ & $\begin{array}{l}\text { Student Fixed } \\
\text { Effects } \\
(2)\end{array}$ & $\begin{array}{c}\text { MSM with IPTW } \\
\text { (Treatment and } \\
\text { Censoring) } \\
(3)\end{array}$ \\
\hline \multicolumn{4}{|l|}{ Math: } \\
\hline High-poverty classroom. . . . & $\begin{array}{c}-.413 * * * \\
(.0191)\end{array}$ & $\begin{array}{c}-.0629 * * * \\
(.0204)\end{array}$ & $\begin{array}{l}.00784 \\
(.0180)\end{array}$ \\
\hline Grade. . . . . . . . . . . & $\begin{array}{c}4.148 * * * \\
(.00453)\end{array}$ & $\begin{array}{l}4.154 * * * \\
(.00455)\end{array}$ & $\begin{array}{l}4.199 * * * \\
(.00466)\end{array}$ \\
\hline Grade $^{2}$ & $\begin{array}{c}-.651 * * * \\
(.00229)\end{array}$ & $\begin{array}{c}-.655^{* * * *} \\
(.00230)\end{array}$ & $\begin{array}{c}-.665 * * * \\
(.00235)\end{array}$ \\
\hline Constant. . . . . . . . . . & $\begin{array}{c}352.5 * * * \\
(.0243)\end{array}$ & $\begin{array}{c}352.6 * * * \\
(.00654)\end{array}$ & $\begin{array}{c}352.3 * * * \\
(.0177)\end{array}$ \\
\hline Observations.......... & 537,653 & 537,653 & 537,653 \\
\hline Reading: & & & \\
\hline High-poverty classroom . . . . & $\begin{array}{c}-.418 * * * \\
(.0221)\end{array}$ & $\begin{array}{l}.106 * * * \\
(.0237)\end{array}$ & $\begin{array}{l}.0545^{*} \\
(.0212)\end{array}$ \\
\hline Grade. . . . . . . . . . & $\begin{array}{l}4.631 * * * \\
(.00520)\end{array}$ & $\begin{array}{l}4.623 * * * \\
(.00524)\end{array}$ & $\begin{array}{l}4.685 * * * \\
(.00540)\end{array}$ \\
\hline Grade $^{2}$ & $\begin{array}{c}-.573 * * * \\
(.00261)\end{array}$ & $\begin{array}{c}-.592 * * * \\
(.00265)\end{array}$ & $\begin{array}{c}-.589 * * * \\
(.00266)\end{array}$ \\
\hline Constant. . . & $\begin{array}{c}349.6 * * * \\
(.0259)\end{array}$ & $\begin{array}{r}349.7 * * * \\
(.00753)\end{array}$ & $\begin{array}{c}349.4 * * * \\
(.0205)\end{array}$ \\
\hline Observations......... & 537,653 & 537,653 & 537,653 \\
\hline
\end{tabular}

Note.-Model 1 of panel A is model 3 from table 3 and model 1 of panel B is model 3 from table 4 (with the same covariates, though only a selection are shown here), reprinted here for comparison purposes. All models control for parent's education, race/ethnicity, gender, and poverty status; race/ethnicity and gender are subsumed into the student-specific intercept in the student fixed-effects model; MSM weights also adjust for school mobility, gifted, special education, limited English proficiency, and grade retention. Robust SEs are in parentheses.

$$
\begin{aligned}
& * P<.05 . \\
& * * P<.01 . \\
& * * * P<.001 .
\end{aligned}
$$

tions produce estimates that are less than $1 \%$ of a standard deviation in effect size in both math and reading.

\section{Growth Model Estimates of Cumulative Exposure to Classroom Poverty}

To address the concern that our estimates presented thus far could potentially underestimate the effect of classroom context by ignoring the cumulative nature of exposure to high-poverty classrooms, in table 6 we present growth model estimates with cumulative exposure to high classroom poverty as the explanatory variable. The random-effects growth model predicts a -2.037 point gap in math between students who up to a point in time were always and never exposed to high-poverty classrooms. This represents $.172 \sigma$ of the math test score, a fairly large effect, which is due in 
TABLE 6

Cumulative Exposure to Classroom Poverty and Achievement: Comparison of Alternative Specifications, 2001-6

\begin{tabular}{|c|c|c|c|}
\hline & $\begin{array}{c}\text { Random } \\
\text { Coefficients } \\
(1)\end{array}$ & $\begin{array}{c}\text { Student Fixed } \\
\text { Effects } \\
(2)\end{array}$ & $\begin{array}{c}\text { MSM with IPTW } \\
\text { (Treatment and } \\
\text { Censoring) } \\
(3)\end{array}$ \\
\hline \multicolumn{4}{|l|}{ Math: } \\
\hline Cumulative poverty exposure. . . & $\begin{array}{c}-2.037 * * * \\
(.0462)\end{array}$ & $\begin{array}{c}-.192 * * * \\
(.0567)\end{array}$ & $\begin{array}{l}.0267 \\
(.0487)\end{array}$ \\
\hline Grade. . . . . . . . . . . & $\begin{array}{c}4.144 * * * \\
(.00455)\end{array}$ & $\begin{array}{c}4.154 * * * \\
(.00455)\end{array}$ & $\begin{array}{l}4.199 * * * \\
(.00465)\end{array}$ \\
\hline Grade $^{2}$ & $\begin{array}{c}-.649 * * * \\
(.00229)\end{array}$ & $\begin{array}{c}-.655^{* * * *} \\
(.00230)\end{array}$ & $\begin{array}{c}-.665 * * * \\
(.00235)\end{array}$ \\
\hline Constant . . & $\begin{array}{c}352.5 * * * \\
(.0241)\end{array}$ & $\begin{array}{r}352.6 * * * \\
(.00654)\end{array}$ & $\begin{array}{c}352.3 * * * \\
(.0178)\end{array}$ \\
\hline Observations . & 537,653 & 537,653 & 537,653 \\
\hline \multicolumn{4}{|l|}{ Reading: } \\
\hline Cumulative poverty exposure. . . & $\begin{array}{c}-2.085 * * * \\
(.0529)\end{array}$ & $\begin{array}{l}.292 * * * \\
(.0668)\end{array}$ & $\begin{array}{l}.263 * * * \\
(.0569)\end{array}$ \\
\hline Grade . . . . . . . . . . & $\begin{array}{c}4.627 * * * \\
(.00522)\end{array}$ & $\begin{array}{l}4.623 * * * \\
(.00524)\end{array}$ & $\begin{array}{l}4.685 * * * \\
(.00540)\end{array}$ \\
\hline Grade $^{2} \ldots$ & $\begin{array}{c}-.572 * * * \\
(.00261)\end{array}$ & $\begin{array}{c}-.593 * * * \\
(.00265)\end{array}$ & $\begin{array}{c}-.589 * * * \\
(.00266)\end{array}$ \\
\hline Constant & $\begin{array}{r}349.6 * * * \\
(.0257)\end{array}$ & $\begin{array}{r}349.7 * * * \\
(.00753)\end{array}$ & $\begin{array}{c}349.4 * * * \\
(.0205)\end{array}$ \\
\hline Observations & 537,653 & 537,653 & 537,653 \\
\hline
\end{tabular}

Note.-All models control for parent's education, race/ethnicity, gender, and poverty status; race/ethnicity and gender are subsumed into the student-specific intercept in the student fixed-effects model; MSM weights also adjust for school mobility, gifted, special education, limited English proficiency, and grade retention. Robust SEs are in parentheses.

$* P<.05$.

$* * P<.01$.

$* * * P<.001$.

part because it is an average of effects across grades 3-8. As shown in the cross-sectional results, the effects of cumulative poverty in third grade are much smaller than the effects in eighth grade. (By eighth grade, an always-exposed student has been in a high-poverty classroom for six years, whereas an always-exposed student in third grade has been exposed only once.) The student fixed-effects model, on the other hand, produces only a -0.192 point gap $(.016 \sigma)$ in math between students who up to a point in time were always and never exposed to high-poverty classrooms. The difference in the two estimates suggests that the large effect produced by the random-coefficients model is largely due to baseline differences in students who become exposed to particularly high and low levels of classroom poverty. The MSM model produces a high-poverty classroom gap that is not significantly different from zero (0.0267), suggesting that time-dependent confounding is downwardly biasing the estimate in column 1 . The pattern in read- 
TABLE 7

Continuous Classroom Poverty and Achievement: Comparison of Alternative SPECIFICATIONS, 2001-6

\begin{tabular}{|c|c|c|}
\hline & $\begin{array}{c}\text { Random } \\
\text { Coefficients } \\
\text { (1) }\end{array}$ & $\begin{array}{c}\text { Student Fixed } \\
\text { Effects } \\
(2)\end{array}$ \\
\hline \multicolumn{3}{|l|}{ Math: } \\
\hline Continuous classroom poverty . . . . & $\begin{array}{l}-.297 * * * \\
(.0104)\end{array}$ & $\begin{array}{l}.0328 * * \\
(.0112)\end{array}$ \\
\hline Grade. . . . . . . . . . . . . . & $\begin{array}{l}4.123 * * * \\
(.00459)\end{array}$ & $\begin{array}{l}4.156 * * * \\
(.00460)\end{array}$ \\
\hline$\ldots \ldots \ldots \ldots \ldots$ & $\begin{array}{c}-.648 * * * \\
(.00229)\end{array}$ & $-.655 * * *$ \\
\hline Constant . . . . . . . . . . . & $\begin{array}{r}352.5 * * * \\
(.0242)\end{array}$ & $\begin{array}{l}352.6 * * * \\
(.00654)\end{array}$ \\
\hline \multicolumn{3}{|l|}{ Reading: } \\
\hline Continuous classroom poverty . . . . & $\begin{array}{c}-.260 * * * \\
(.0118)\end{array}$ & $\begin{array}{l}.224 * * * \\
(.0131)\end{array}$ \\
\hline Grade. . . . . . . . & $\begin{array}{l}4.610 * * * \\
(.00529)\end{array}$ & $\begin{array}{l}4.637 * * * \\
(.00529)\end{array}$ \\
\hline Grade $^{2}$. & $\begin{array}{c}-.571 * * * \\
(.00261)\end{array}$ & $\begin{aligned}-.592 * * * \\
(.00265)\end{aligned}$ \\
\hline Constant . . . . . . . & $\begin{array}{c}349.6 * * * \\
(.0258)\end{array}$ & $\begin{array}{l}349.7 * * * \\
(.00753)\end{array}$ \\
\hline Observations ............ & 537,653 & 537,653 \\
\hline
\end{tabular}

NoTE.-All models control for parent's education, race/ethnicity, gender, and poverty status; race/ethnicity and gender are subsumed into the student-specific intercept in the student fixed-effects model; MSM weights also adjust for school mobility, gifted, special education, limited English proficiency, and grade retention. Robust SEs are in parentheses.

$* P<.05$.

$* * P<.01$.

$* * * P<.001$.

ing is largely the same, with a large negative effect from the random-effects growth model $(.161 \sigma)$ shrinking closer toward zero in the fixed-effects $(.023 \sigma)$ and MSM specifications $(.022 \sigma)$. The unexpected result is that the sign of the cumulative poverty effect is positive in the fixed-effect and MSM specifications rather than negative.

\section{Growth Model Estimates of Continuous Poverty}

For consistency with prior research that uses continuous measures of poverty context, we present the effect of a standardized measure of continuous classroom poverty (measured as the percentage of students in the classroom who are on free or reduced-priced lunch) in table 7 . We present estimates

${ }^{11}$ Owing to the complexity of calculating IPT weights for continuous treatments, we do not present MSM results for standardized classroom poverty. 
American Journal of Sociology

from the random-coefficients and fixed-effects models. ${ }^{11}$ In column 1, a $1-\mathrm{SD}$ increase in classroom poverty produces a 0.297 decrease in math test score $(-.025 \sigma)$. The estimate from a student fixed-effects model produces an effect with the opposite sign but much smaller in absolute value $(+.003 \sigma)$. In reading, the signs of the effects from the random-coefficients and fixedeffects specifications are also opposite signed, and both are approximately the same size, producing effect sizes of $-.002 \sigma$ and $+.017 \sigma$, for a 1-SD increase in classroom poverty.

\section{Effect Size Summary with 95\% Confidence Intervals}

Most of the reported effects are statistically significant yet small in substantive terms. Our claim that the contextual effects found in this study are small would fail if confidence intervals contain values that could be considered large. Because of the large sample size used in this study, however, confidence intervals are quite narrow (table 8). For example, in panel A of table 8 we show that $95 \%$ confidence intervals of standardized fixed-effects high-poverty classroom estimates ( 0 to 1 contrast) are between -.009 and -.002 in math and .005 and .012 in reading. The MSM confidence intervals are also tightly clustered around zero. Panel B shows that the fixed-effect cumulative poverty effects ( 0 to 1 contrast) in math and reading lie within the range of -.026 (lower bound for math) and .033 (upper bound for reading); the MSM results for the cumulative poverty effect are between -.006 and .031 .

For continuous classroom poverty we report effects from two contrasts: a 1- and 2-SD increase in classroom poverty. To put these contrasts into perspective, $32 \%$ of students experience one instance of an increase in classroom poverty of 25 percentage points or more ( $1 \mathrm{SD})$. Only $5 \%$ of students experience an increase of 50 percentage points (2 SD). The effects for a 1-SD effect from the random-coefficient and fixed-effects specifications are within the range of -.027 to +.019 , whereas the effects for a 2-SD effect from these two specifications are within -.054 to +.039 . Given that most effects reported from the student fixed-effects and MSM models are smaller than $.04 \sigma$ in absolute value, we conclude that the contextual effects of classroom poverty on cognitive achievement are very small.

\section{CONCLUSION}

For decades scholars from a variety of disciplines have been debating the size of contextual effects on youth outcomes. What do we add to this rich literature? This study moves beyond a conception of contextual effects as correlations estimated on young people at one point in time. Our findings challenge previous research based on cross-sectional designs, most of which 


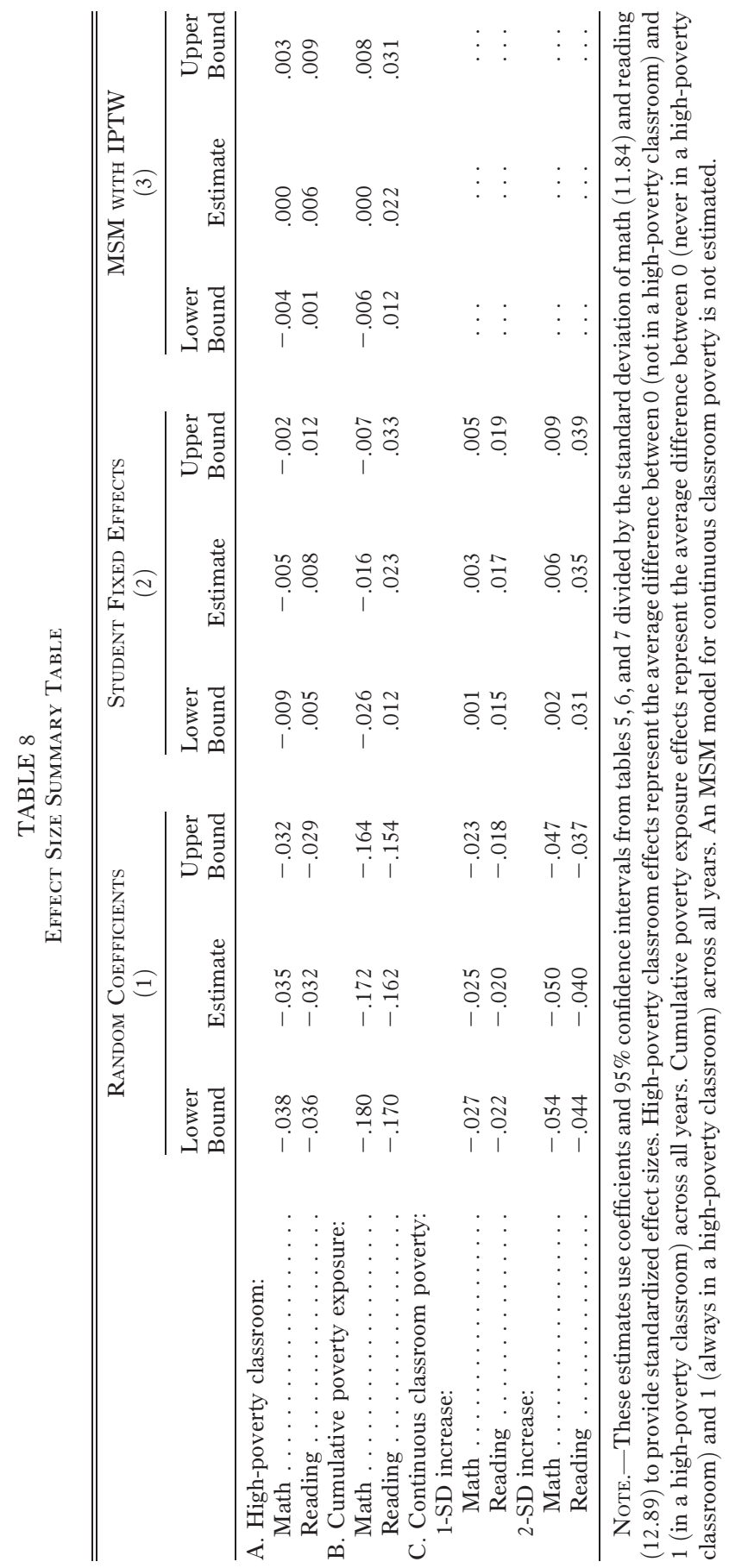


report negative effects of peer poverty on student achievement. With crosssectional models, we replicate past research by establishing that exposure to high-poverty classrooms is negatively associated with math test score, with the strength of the association becoming quite large as students increase in grade level. The growth model evidence presented, however, shows very small negative effects of exposure to a high-poverty classroom and continuous classroom poverty on math and reading test scores. Models with student fixed effects, which control for time-invariant student background unobservables, and models with inverse-probability-of-treatment weighting, which properly adjusts for observable time-dependent confounding, produce negligible effects of all three measures of classroom poverty on math and reading achievement.

The fact that exposure to classroom poverty has a strong association wit test score in the cross section but has very small effects in models with weaker assumptions for causal inference strongly suggests that selection bias is present in the cross-sectional estimates derived from point-in-time correlations. Whether the effect of school poverty is causal or simply is a function of either omitted variable bias or endogenous self-selection is a critical conceptual and empirical matter for both the theory of school effects and policies that seek to integrate students by socioeconomic background (Duncan and Raudenbush 1999).

This study has important implications for both research and public policy. The findings suggest that standard estimates and prevailing theories about social influence among preadolescents and early adolescents may not hold for test score achievement, one of the most important educational outcomes. This suggests that simply mixing students by poverty level without altering important institutional resources such as high-quality instruction or teacher expectations may not have the intended effect of increasing achievement because achievement is not a function simply of poverty context but of student and family background. The policy goal of mixing students by race or ethnicity or social background has been a mainstay in educational policy since the Brown vs. Board decision. Since the 1980s, school desegregation orders have been vacated by an increasingly conservative judiciary. The changing legal landscape has contributed to a resegregation of American schools (Orfield, Eaton, and Harvard Project on School Desegregation 1996; Reardon and Yun 2005; Rumberger and Palardy 2005). In 2007 the Supreme Court ruled in Parents Involved v. Seattle School District No. 1 that school districts may not use race in assigning students or granting transfers to achieve or maintain school integration. In response some now advocate for integrating students by socioeconomic background (Kahlenberg 2001), which is constitutionally permissible. Kahlenberg argues that the best way to ensure the presence of high standards, highly qualified teachers, and less crowded classes is to ensure that each school has a critical 
mass of middle-class families to advocate for these resources. Various forms of SES integration have been implemented in more than 50 districts across the United States, including Lacrosse, Wisconsin; Wake County, North Carolina; Cambridge, Massachusetts; and San Francisco, California. The findings of the present study suggest that simply mixing students by social background may not have the intended effects, unless such mixing can garner increased resources and support for proven teaching practices that can increase student achievement in impoverished contexts.

This study has some limitations that point the way for future work on school and classroom poverty effects. Although North Carolina is racially and economically diverse, the study covers the public school students from only one state, which limits the generalizability of our findings. Using population-level administrative data, we have pursued an identification strategy that privileges reduction of bias over national representativeness. The external validity of these results hinges on replications from other states using administrative data and on large nationally representative surveys with rich contextual information and interval metric test scores designed to measure growth over time. We must stress that we use a research design that reduces, but may not entirely eliminate, bias from unobservables. For example, accounting for more time-varying student or school unobservables could prove these estimates to be biased. Future work should carefully theorize and measure time-varying factors that predict test scores. We cannot empirically examine whether changes in classroom poverty correspond to substantial differences in microlevel interaction between students and between students and teachers. An important next step for school contextual effects research is to examine the effect of school or classroom poverty on test score growth. Although our models suggest negligible effects of classroom poverty on average test score achievement across students' third through eighth grade panels, it is still possible that school or classroom poverty negatively deflects students' growth rates. Moreover, contextual effects may vary by a number of demographic characteristics such as race, individual poverty status, or gender (Clampet-Lundquist et al. 2011; Legewie and DiPrete 2012). Finally, even if test scores are largely impervious to the influence of peers and socialization, other outcomes such as pregnancy, drug use, school completion, and college attendance may be more responsive to these influences than a test score, which is a product of skills that take a long time to learn.

Much of the existing research on contextual effects has examined the experiences and outcomes of high school students. This study represents one of the first sociological examinations of contextual effects among elementary and middle school students. Despite this contribution, it may be that even by third grade, which is the earliest time point in this study, prior childhood experiences have largely determined a student's potential 


\section{American Journal of Sociology}

achievement. If test score gaps among socioeconomic groups are essentially stable by third grade and variations in school quality have little effect on these gaps over time (Heckman 2006), then policies to mix students by social background may be of limited utility. On the other hand, research has found neighborhood effects on birth weight and other early childhood development experiences (e.g., Chase-Lansdale et al. 1997; Morenoff 2003; Masi et al. 2007). Therefore, a promising avenue for future research may be the investigation of pregnant mothers' and younger children's sensitivity to impoverished contexts, preferably with research designs that permit accounting for unobserved family or individual heterogeneity and timedependent confounding.

\section{APPENDIX}

TABLE A1

Comparison of Pre- and Postimputation Descriptive Statistics

\begin{tabular}{|c|c|c|c|c|c|c|}
\hline & \multicolumn{3}{|c|}{ Preimputation } & \multicolumn{3}{|c|}{ Postimputation } \\
\hline & $N$ & Mean & $\mathrm{SD}$ & $N$ & Mean & $\mathrm{SD}$ \\
\hline \multicolumn{7}{|l|}{ Dependent variables: } \\
\hline Math test score.... & 550,147 & 350.72 & 11.86 & 537,653 & 350.78 & 11.84 \\
\hline Reading test score . . . . . . . . . . & 548,301 & 348.11 & 12.91 & 537,653 & 348.04 & 12.89 \\
\hline \multicolumn{7}{|l|}{ Student background: } \\
\hline $\begin{array}{l}\text { Parent has high school diploma } \\
\text { or less } \ldots \ldots \ldots \ldots \ldots \ldots \ldots\end{array}$ & 551,906 & .53 & .50 & 537,653 & .53 & .42 \\
\hline $\begin{array}{l}\text { Parent has some postsecondary } \\
\text { education } \ldots \ldots \ldots \ldots \ldots\end{array}$ & 551,906 & .21 & .41 & 537,653 & .21 & .41 \\
\hline Parent has bachelor's degree or & & & & & & \\
\hline 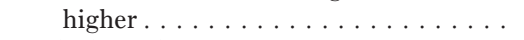 & 551,906 & .26 & .44 & 537,653 & .27 & .44 \\
\hline Black student . . . . . . . . . . . & 558,353 & .31 & .46 & 537,653 & .30 & .46 \\
\hline Hispanic student. . . & 558,353 & .05 & .22 & 537,653 & .05 & .22 \\
\hline Other racial/ethnic background . . . . . & 558,353 & .05 & .23 & 537,653 & .05 & .22 \\
\hline Male student. . . . . . . . . . . & 558,353 & .51 & .50 & 537,653 & .50 & .50 \\
\hline Student was designated gifted . . . . . . & 558,353 & .14 & .35 & 537,653 & .14 & .35 \\
\hline Student received special education & & & & & & \\
\hline services . . . . . . . . . . & 557,862 & .12 & .33 & 537,653 & .11 & .32 \\
\hline Student showed limited English & & & & & & \\
\hline proficiency. & 557,931 & .02 & .15 & 537,653 & .02 & .15 \\
\hline Student was ever retained . . . . & 552,791 & .11 & .32 & 537,653 & .11 & .32 \\
\hline Student received free or reduced-price & & & & & & \\
\hline lunch $\ldots \ldots \ldots \ldots \ldots \ldots$ & 544,289 & .46 & .50 & 537,653 & .45 & .50 \\
\hline Student made a structural school & & & & & & \\
\hline move $\ldots \ldots \ldots \ldots \ldots \ldots$ & 558,353 & .16 & .36 & 537,653 & .16 & .37 \\
\hline Student made a nonstructural school & & & & & & \\
\hline move $\ldots \ldots \ldots \ldots \ldots \ldots$ & 558,353 & .09 & .29 & 537,653 & .09 & .28 \\
\hline Peer po & & & & & & \\
\hline High-poverty classroom. . . . . . . . . & 558,353 & .24 & .43 & 537,653 & .24 & .43 \\
\hline $\begin{array}{l}\text { Cumulative exposure to high-poverty } \\
\text { classrooms } \ldots \ldots \ldots \ldots \ldots \ldots \ldots\end{array}$ & 558,353 & .24 & .35 & 537,653 & .23 & .35 \\
\hline Continuous classroom poverty . . & 558,353 & .45 & .27 & 537,653 & .45 & .26 \\
\hline
\end{tabular}


Exposure to Classroom Poverty

TABLE A1 (Continued)

\begin{tabular}{|c|c|c|c|c|c|c|}
\hline & \multicolumn{3}{|c|}{ PREIMPUTATION } & \multicolumn{3}{|c|}{ Postimputation } \\
\hline & $N$ & Mean & $\mathrm{SD}$ & $N$ & Mean & $\mathrm{SD}$ \\
\hline \multicolumn{7}{|c|}{ Time variables: } \\
\hline Grade. & 558,353 & 5.34 & 1.70 & 537,653 & 5.34 & 1.69 \\
\hline Grade $^{2}$ & 558,353 & 31.43 & 18.58 & 537,653 & 31.41 & 18.50 \\
\hline
\end{tabular}

Note.-Observations reported are student-year observations; 4,108 student-year observations were dropped before imputation because of a student having $<50 \%$ valid math scores in his or her panel (1,266 for reading).

\section{REFERENCES}

Alexander, Karl, and Bruce K. Eckland. 1975. "Contextual Effects in High-School Attainment Process." American Sociological Review 40 (3): 402-16.

Alexander, Karl L., James Fennessey, Edward L. McDill, and Ronald J. D'Amico. 1979. "School SES Influences-Composition or Context?" Sociology of Education 52 (4): 222-37.

Allison, Paul D. 2009. Fixed Effects Regression Models. Thousand Oaks, Calif.: Sage.

Attewell, Paul. 2001. "The Winner-Take-All High School: Organizational Adaptations to Educational Stratification." Sociology of Education 74 (4): 267-95.

Bachman, Jerald G., and Patrick M. O’Malley. 1986. "Self-Concepts, Self-Esteem, and Educational-Experiences - the Frog Pond Revisited (Again).” Journal of Personality and Social Psychology 50 (1): 35-46.

Barr, Rebecca, and Robert Dreeben. 1983. How Schools Work. Chicago: University of Chicago Press.

Battistich, Victor, Daniel Solomon, Dong-il Kim, Marilyn Watson, and Eric Schaps. 1995. "Schools as Communities, Poverty Levels of Student Populations, and Students' Attitudes, Motives, and Performance: A Multilevel Analysis." American Educational Research Journal 32 (3): 627-58.

Bazelon, Emily. 2008. "The Next Kind of Integration.” New York Times Magazine, July 20.

Brooks-Gunn, Jeanne, Greg J. Duncan, Pamela Kato Klebanov, and Naomi Sealand. 1993. "Do Neighborhoods Influence Child and Adolescent Development?" American Journal of Sociology 99 (2): 353-95.

Bryk, Anthony S., and Stephen W. Raudenbush. 1987. "Application of Hierarchical Linear-Models to Assessing Change.” Psychological Bulletin 101 (1): 147-58.

Buchmann, Claudia, and Ben Dalton. 2002. "Interpersonal Influences and Educational Aspirations in 12 Countries: The Importance of Institutional Context." Sociology of Education 75 (2): 99-122.

Chase-Lansdale, P. Lindsay, Rachel A. Gordon, Jeanne Brooks-Gunn, and Pamela Kato Klebanov. 1997. "Neighborhood and Family Influences on the Intellectual and Behavioral Competence of Preschool and Early School-Age Children." Pp. 79-118 in Neighborhood Poverty, vol. 2, Context and Consequences for Children, edited by Jeanne BrooksGunn, Greg J. Duncan, and J. Lawrence Aber. New York: Russell Sage Foundation.

Choi, Kate H., R. Kelly Raley, Chandra Muller, and Catherine Riegle-Crumb. 2008. "Class Composition: Socioeconomic Characteristics of Coursemates and College Enrollment." Social Science Quarterly 89 (4): 846-66.

Clampet-Lundquist, Susan, Kathryn Edin, Jeffrey R. Kling, and Greg J. Duncan. 2011. "Moving Teenagers Out of High-Risk Neighborhoods: How Girls Fare Better Than Boys.” American Journal of Sociology 116 (4): 1154-89. 


\section{American Journal of Sociology}

Cole, S. R., and M. A. Hernán. 2008. "Constructing Inverse Probability Weights for Marginal Structural Models.” American Journal of Epidemiology 168 (6): 656-64.

Cole, S. R., R. W. Platt, E. F. Schisterman, H. Chu, D. Westreich, D. Richardson, and C. Poole. 2010. "Illustrating Bias Due to Conditioning on a Collider." International Journal of Epidemiology 39 (2): 417-20.

Coleman, James S., Ernest Q. Campbell, Carol J. Hobson, James McPartland, Alexander J. Mood, Frederic D. Weinfeld, and Robert L. York. 1966. Equality of Educational Opportunity. Washington, D.C.: Government Printing Office.

Crane, Jonathan. 1991. "The Epidemic Theory of Ghettos and Neighborhood Effects on Dropping Out and Teenage Childbearing." American Journal of Sociology 96 (5): 1226-59.

Crosnoe, Robert. 2009. "Low-Income Students and the Socioeconomic Composition of Public High Schools.” American Sociological Review 74 (5): 709-30.

Crowder, Kyle, and Scott J. South. 2011. "Spatial and Temporal Dimensions of Neighborhood Effects on High School Graduation." Social Science Research 40 (1): 87-106.

Dauber, Susan L., Karl L. Alexander, and Doris R. Entwisle. 1996. "Tracking and Transitions through the Middle Grades: Channeling Educational Trajectories.” Sociology of Education 69 (4): 290-307.

Davis, James A. 1966. "Campus as a Frog Pond: An Application of the Theory of Relative Deprivation to Career Decisions of College Men.” American Journal of Sociology 72 (1): $17-31$.

DeLuca, Stefanie, and Elizabeth Dayton. 2009. "Switching Social Contexts: The Effects of Housing Mobility and School Choice Programs on Youth Outcomes." Annual Review of Sociology 35:457-91.

Duncan, Greg J. 1994. "Families and Neighbors as Sources of Disadvantage in the Schooling Decisions of White and Black Adolescents." American Journal of Education 103 (1): 20-53.

Duncan, Greg J., and Jeanne Brooks-Gunn. 1997. Consequences of Growing Up Poor. New York: Russell Sage Foundation.

Duncan, Greg J., and Stephen W. Raudenbush. 1999. "Assessing the Effects of Context in Studies of Child and Youth Development." Educational Psychologist 34 (1): 29-41.

England, Paula, Paul D. Allison, and Yuxiao Wu. 2007. "Does Bad Pay Cause Occupations to Feminize, Does Feminization Reduce Pay, and How Can We Tell with Longitudinal Data?" Social Science Research 36 (3): 1237-56.

Entwisle, Doris R., Karl L. Alexander, and Linda S. Olson. 1994. "The Gender Gap in Math: Its Possible Origins in Neighborhood Effects." American Sociological Review 59 (6): 822-38.

_. 2005. "First Grade and Educational Attainment by Age 22: A New Story." American Journal of Sociology 110 (5): 1458-1502.

Evans, William N., Wallace E. Oates, and Robert M. Schwab. 1992. "Measuring Peer Group Effects: A Study of Teenage Behavior.” Journal of Political Economy 100 (5): 966-91.

Felmlee, Diane, and Donna Eder. 1983. "Contextual Effects in the Classroom-the Impact of Ability Groups on Student Attention." Sociology of Education 56 (2): 77-87.

Furman, Wyndol. 1982. "Children's Friendships." Pp. 327-39 in Review of Human Development, edited by Tiffany M. Field. New York: Wiley.

Galster, George, Dave E. Marcotte, Marv Mandell, Hal Wolman, and Nancy Augustine. 2007. "The Influence of Neighborhood Poverty during Childhood on Fertility, Education, and Earnings Outcomes." Housing Studies 22 (5): 723-51.

Gamoran, Adam. 1987. "The Stratification of High-School Learning Opportunities." Sociology of Education 60 (3): 135-55.

Garner, Catherine L., and Stephen W. Raudenbush. 1991. "Neighborhood Effects on Educational Attainment: A Multilevel Analysis." Sociology of Education 64 (4): 251-62. 


\section{Exposure to Classroom Poverty}

Grant, Gerald. 2009. Hope and Despair in the American City. Cambridge, Mass.: Harvard University Press.

Greenland, S. 2003. "Quantifying Biases in Causal Models: Classical Confounding vs Collider-Stratification Bias.” Epidemiology 14 (3): 300-306.

Halaby, Charles N. 2004. "Panel Models in Sociological Research: Theory into Practice." Annual Review of Sociology 30:507-44.

Hallinan, Maureen T. 1992. "The Organization of Students for Instruction in Middle School." Sociology of Education 65 (2): 114-27.

Hanushek, Eric A., John F. Kain, and Steven G. Rivkin. 2009. "New Evidence about Brown v. Board of Education: The Complex Effects of School Racial Composition on Achievement." Journal of Labor Economics 27 (3): 349-83.

Harding, David J. 2003. "Counterfactual Models of Neighborhood Effects: The Effect of Neighborhood Poverty on Dropping Out and Teenage Pregnancy." American Journal of Sociology 109 (3): 676-719.

Harris, Douglas N. 2010. "How Do School Peers Influence Student Educational Outcomes? Theory and Evidence from Economics and Other Social Sciences." Teachers College Record 112 (4): 1163-97.

Hauser, Robert M. 1970. "Context and Consex: A Cautionary Tale." American Journal of Sociology 75 (4): 645-64.

Heckman, James J. 2006. "Skill Formation and the Economics of Investing in Disadvantaged Children.” Science 312 (5782): 1900-1902.

Hernán, Miguel Angel, Babette Brumback, and James M. Robins. 2000. "Marginal Structural Models to Estimate the Causal Effect of Zidovudine on the Survival of HIVPositive Men.” Epidemiology 11 (5): 561-70.

Hernán, Miguel Angel, S. Hernández-Díaz, and J. M. Robins. 2004. "A Structural Approach to Selection Bias.” Epidemiology 15 (5): 615-25.

Hong, Guanglei, and Stephen W. Raudenbush. 2008. "Causal Inference for Time-Varying Instructional Treatments." Journal of Educational and Behavioral Statistics 33 (3): 333-62.

Hoxby, Caroline M., and Gretchen Weingarth. 2005. "Taking Race Out of the Equation: School Reassignment and the Structure of Peer Effects.” Working paper. Harvard University.

Jackson, Margot I., and Robert D. Mare. 2007. "Cross-Sectional and Longitudinal Measurements of Neighborhood Experience and Their Effects on Children." Social Science Research 36 (2): 590-610.

Jacobs, David, and Jason T. Carmichael. 2001. "The Politics of Punishment across Time and Space: A Pooled Time-Series Analysis of Imprisonment Rates.” Social Forces 80 (1): 61-89.

Jacobs, David, and Daniel Tope. 2007. "The Politics of Resentment in the Post-Civil Rights Era: Minority Threat, Homicide, and Ideological Voting in Congress." American Journal of Sociology 112 (5): 1458-94.

Jencks, Christopher, and Susan E. Mayer. 1990. "The Social Consequences of Growing Up in a Poor Neighborhood.” Pp. 111-86 in Inner-City Poverty in the United States, edited by Laurence E. Lynn and Michael G. H. McGeary. Washington, D.C.: National Academy Press.

Kahlenberg, Richard D. 2001. All Together Now: Creating Middle-Class Schools through Public School Choice. Washington, D.C.: Brookings Institution Press.

Kling, Jeffrey R., Jeffrey B. Liebman, and Lawrence F. Katz. 2007. "Experimental Analysis of Neighborhood Effects.” Econometrica 75 (1): 83-119.

Kocak, Ozgecan, and Glenn R. Carroll. 2008. "Growing Church Organizations in Diverse U.S. Communities, 1890-1926.” American Journal of Sociology 113 (5): 1272 1315.

Lee, Valerie E., Anthony S. Bryk, and Julia B. Smith. 1993. "The Effects of High School Organization on Teachers and Students." Pp. 171-268 in Review of Research in Edu- 


\section{American Journal of Sociology}

cation, edited by Linda Darling-Hammond. Washington, D.C.: American Educational Research Association.

Legewie, Joscha, and Thomas A. DiPrete. 2012. "School Context and the Gender Gap in Educational Achievement." American Sociological Review 77 (3): 463-85.

Leventhal, Tama, and Jeanne Brooks-Gunn. 2000. "The Neighborhoods They Live In: The Effects of Neighborhood Residence on Child and Adolescent Outcomes." Psychological Bulletin 126 (2): 309-37.

Luo, Wen, and Oi-man Kwok. 2009. "The Impacts of Ignoring a Crossed Factor in Analyzing Cross-Classified Data.” Multivariate Behavioral Research 44 (2): 182-212.

Manski, Charles F. 1993. "Identification of Endogenous Social Effects- the Reflection Problem." Review of Economic Studies 60 (3): 531-42.

Marsh, Herbert W. 1987. "The Big-Fish Little-Pond Effect on Academic Self-Concept." Journal of Educational Psychology 79 (3): 280-95.

Marsh, Herbert W., and John W. Parker. 1984. "Determinants of Student Self-ConceptIs It Better to Be a Relatively Large Fish in a Small Pond Even If You Don't Learn to Swim as Well?" Journal of Personality and Social Psychology 47 (1): 213-31.

Masi, Christopher M., Louise C. Hawkley, Z. Harry Piotrowski, and Kate E. Pickett. 2007. "Neighborhood Economic Disadvantage, Violent Crime, Group Density, and Pregnancy Outcomes in a Diverse, Urban Population." Social Science and Medicine 65 (12): 2440-57.

Morenoff, Jeffrey D. 2003. "Neighborhood Mechanisms and the Spatial Dynamics of Birth Weight.” American Journal of Sociology 108 (5): 976-1017.

Mouw, Ted. 2003. "Social Capital and Finding a Job: Do Contacts Matter?" American Sociological Review 68 (6): 868-98.

- 2006. "Estimating the Causal Effect of Social Capital: A Review of Recent Research.” Annual Review of Sociology 32:79-102.

Orfield, Gary, Susan E. Eaton, and Harvard Project on School Desegregation. 1996. Dismantling Desegregation: The Quiet Reversal of Brown v. Board of Education. New York: New Press.

Orfield, Gary R., Erica Frankenberg, and Liliana M. Garces. 2008. "Statement of American Social Scientists of Research on School Desegregation to the U.S. Supreme Court in Parents v. Seattle School District and Meredith v. Jefferson County." Urban Review 40 (1): 96-136.

Orr, Larry, Judith D. Feins, Robin Jacob, Erik Beercroft, Lisa Sanbonmatsu, Lawrence F. Katz, Jeffrey B. Liebman, and Jeffrey R. Kling. 2003. Moving to Opportunity: Interim Impacts Evaluation. Washington, D.C.: U.S. Department of Housing and Urban Development.

Owens, Ann. 2010. "Neighborhoods and Schools as Competing and Reinforcing Contexts for Educational Attainment.” Sociology of Education 83 (4): 287-311.

Quigley, John M., and Steven Raphael. 2008. "Neighborhoods, Economic Self-Sufficiency, and the MTO." Brookings-Wharton Papers on Urban Affairs 3:1-46.

Reardon, Sean F., and John T. Yun. 2005. "Integrating Neighborhoods, Segregating Schools: The Retreat from School Desegregation in the South, 1990-2000." Pp. 5169 in School Resegregation: Must the South Turn Back? edited by John Charles Boger and Gary Orfield. Chapel Hill: University of North Carolina Press.

Robins, James M. 1999. "Association, Causation, and Marginal Structural Models." Synthese 121:151-79.

Robins, James M., Miguel Angel Hernán, and Babette Brumback. 2000. "Marginal Structural Models and Causal Inference in Epidemiology." Epidemiology 11 (5): 550-60.

Rumberger, Russell W., and Gregory J. Palardy. 2005. "Does Segregation Still Matter? The Impact of Student Composition on Academic Achievement in High School." Teachers College Record 107 (9): 1999-2045. 
Rumberger, Russell W., and J. Douglas Willms. 1992. "The Impact of Racial and Ethnic Segregation on the Achievement Gap in California High Schools." Educational Evaluation and Policy Analysis 14 (4): 377-96.

Sampson, Robert J. 2008. "Moving to Inequality: Neighborhood Effects and Experiments Meet Social Structure." American Journal of Sociology 118 (1): 189-231.

Sampson, Robert J., Patrick Sharkey, and Stephen W. Raudenbush. 2008. "Durable Effects of Concentrated Disadvantage on Verbal Ability among African-American Children." Proceedings of the National Academy of Sciences of the United States of America 105 (3): 845-52.

Sanbonmatsu, Lisa, Jeffrey R. Kling, Greg J. Duncan, and Jeanne Brooks-Gunn. 2006. "Neighborhoods and Academic Achievement: Results from the Moving to Opportunity Experiment." Journal of Human Resources 41 (4): 649-91.

Saporito, Salvatore, and Deenesh Sohoni. 2007. "Mapping Educational Inequality: Concentrations of Poverty among Poor and Minority Students in Public Schools." Social Forces 85 (3): 1227-53.

Schneiberg, Marc, Marissa King, and Thomas Smith. 2008. "Social Movements and Organizational Form: Cooperative Alternatives to Corporations in the American Insurance, Dairy, and Grain Industries." American Sociological Review 73 (4): 635-67.

Sedlak, Michael W., Christopher W. Wheeler, Diana C. Pullin, and Philip A. Cusick. 1986. Selling Students Short: Classroom Bargains and Academic Reform in the American Classroom. New York: Teachers College Press.

Sharkey, Patrick, and Felix Elwert. 2011. "The Legacy of Disadvantage: Multigenerational Neighborhood Effects on Cognitive Ability." American Journal of Sociology 116 (6): 1934-81.

Singer, Judith D., and John B. Willett. 2003. Applied Longitudinal Data Analysis. New York: Oxford University Press.

Solon, Gary, Marianne E. Page, and Greg J. Duncan. 2000. "Correlations between Neighboring Children in Their Subsequent Educational Attainment." Review of Economics and Statistics 82 (3): 383-92.

South, Scott J., Eric P. Baumer, and Amy Lutz. 2003. "Interpreting Community Effects on Youth Educational Attainment." Youth and Society 35 (1): 3-36.

Veronneau, Marie-Helene, and Thomas J. Dishion. 2011. "Middle School Friendships and Academic Achievement in Early Adolescence: A Longitudinal Analysis." Journal of Early Adolescence 31 (1): 99-124.

Willms, J. Douglas. 1986. "Social Class Segregation and Its Relationship to Pupils' Examination Results in Scotland." American Sociological Review 51 (2): 224-41.

. 2010. "School Composition and Contextual Effects on Student Outcomes." Teachers College Record 112 (4): 1008-38.

Wilson, Alan B. 1959. "Residential Segregation of Social-Classes and Aspirations of High-School Boys." American Sociological Review 24 (6): 836-45.

Wodtke, Geoffrey T., David J. Harding, and Felix Elwert. 2011. "Neighborhood Effects in Temporal Perspective: The Impact of Long-Term Exposure to Concentrated Disadvantage on High School Graduation." American Sociological Review 76 (5): 713-36.

Wooldridge, Jeffrey M. 2003. Introductory Econometrics: A Modern Approach. Cincinnati: South-Western College Publishing. 